\title{
Climate change impacts on wind speeds and wind energy density in northern Europe: empirical downscaling of multiple AOGCMs
}

\author{
S. C. Pryor ${ }^{1, *}$, J. T. Schoof ${ }^{1,3}$, R. J. Barthelmie ${ }^{2,1}$ \\ ${ }^{1}$ Atmospheric Science Program, Department of Geography, Indiana University, Bloomington, Indiana 47405, USA \\ ${ }^{2}$ Department of Wind Energy and Atmospheric Physics, Risø National Laboratory, 4000 Roskilde, Denmark \\ ${ }^{3}$ Present address: Center for Ocean-Atmospheric Prediction Studies, The Florida State University, Tallahassee, \\ Florida 32310, USA
}

\begin{abstract}
We present empirical downscaling of 5 state-of-the-art AOGCMs (Atmosphere-Ocean General Circulation Models) to investigate potential changes in wind speeds and energy density in northern Europe. The approach is based on downscaling the Weibull parameters of wind speed probability distributions from AOGCM-derived $500 \mathrm{hPa}$ relative vorticity and sea-level pressure gradients, and is demonstrated to generate accurate depictions of the wind climate during the transfer function conditioning period. Bootstrapping is used to develop 100 realizations for each downscaling period and these are used to assess the uncertainty in the results due to stochastic effects in the AOGCM-derived downscaling predictors. Projected changes in the wind speed probability distribution vary with the AOGCMs from which the predictors are derived, but generally it is shown that mean wind speeds, 90th percentile wind speeds and energy density are slightly lower in the 2081-2100 climate projection period than during 1961-1990 at the majority of the 46 stations studied. Conversely it is found that there is no significant difference between conditions during 2046-2065 and 1961-1990 based on the ensemble of downscaling results. Equally, the winter time of 2046-2065 is largely indistinguishable from 1961-1990 for the majority of stations, while the winters of 2081-2100 appear to be associated with lower mean and 90th percentile wind speeds and energy density.
\end{abstract}

KEY WORDS: Wind speeds $\cdot$ AOGCM $\cdot$ Climate projections $\cdot$ Empirical downscaling

\section{INTRODUCTION}

Potential changes to wind regimes as a result of an evolving global climate have received less attention from the climate community than either temperature or precipitation, and those studies that have addressed atmospheric flow regimes tend to focus on storm climates (Lionello et al. 2003, Lozano et al. 2004, Weisse et al. 2005) and wind speed extremes (Kharin \& Zwiers 2000, Yan et al. 2002), or gusts (Jungo et al. 2002). Changes in the probability distribution of wind speeds have consequences for thermal comfort, structural design (Ambrose \& Vergun 1997), wind energy (Sailor et al. 2000), agriculture and forestry (Nilsson et al. 2004), erosion (Arbogast et al. 1997) and evapotranspi- ration (Hsu 1988). In addition, wind and wave fields are strongly coupled (Lionello et al. 2003), and changing near-surface wind speeds impact both surface fluxes (Simmonds \& Keay 2002) and surface roughness (Knippertz et al. 2000) as well as ocean mixing (Yang et al. 2004).

Due to the relatively high degree of spatial heterogeneity (see for example Fig. 1), wind speeds have to be downscaled from large-scale AOGCM (AtmosphereOcean General Circulation Model) output for impact studies (Bogardi \& Matyasovszky 1996, Lionello et al. 2003). Dynamical downscaling might be considered theoretically superior, but rigorous comparisons are few in number (Mearns et al. 1999), and empirical modeling has been shown to give comparable or better per- 
formance than regional coupled models for some parameters (Kidson \& Thompson 1998, Goddard et al. 2001). Empirical downscaling may prove preferable in the current context due to the need to reproduce local rather than mesoscale wind speeds for many applications (dynamical models run at scales of 10 to $40 \mathrm{~km}$ are unable to capture the full variability of $10 \mathrm{~m}$ wind speeds; de Rooy \& Kok 2004, Räisänen et al. 2004).

Pryor et al. (2005c) present a novel approach to empirical downscaling of wind speeds where the predictands are the parameters of the wind speed probability distribution at a specific location (rather than time series of wind speeds) (Sailor et al. 2000, Lionello et al. 2003) and the predictors are parameters of the probability distributions of the sea-level pressure gradient and $500 \mathrm{hPa}$ relative vorticity. We propose that this approach is advantageous because: (1) It avoids a focus on mean conditions and underestimation of variance (due to truncation of the probability distribution), and hence generates a more robust representation of the upper percentiles of the wind speed probability distribution. (2) It generates output that is accessible to, and more strongly coupled to, the needs of user communities such as the wind energy industry who are familiar with Weibull distribution statistics and use them routinely to assess wind energy density. (3) It avoids difficulties associated with reproducing the time structure of wind speeds, while offering the end user the opportunity to reconstruct a time series conforming to the derived probability distribution parameters. (4) Observations and AOGCM output are frequently either displaced in time and/or sampling interval requiring a time adjustment or averaging to longer sampling times (Huth 2005). However, this technique does not resolve changes in wind direction, and although a time series can be derived from the probability distribution parameters the temporal autocorrelation must be independently applied.

Here we extend the approach of Pryor et al. (2005c) by implementing a bootstrap resampling technique (Lunneborg 2000) to ascertain the uncertainty in derived Weibull parameters and applying our downscaling approach to output from 5 coupled AOGCMs made available for the upcoming 4th Assessment Report of the Intergovernmental Panel on Climate Change (IPCC).

\section{STUDY REGION AND DATA SETS}

\subsection{Study area}

The geographic focus of this research is northern Europe, and specifically the Baltic region (Fig. 1). Increased prevalence of higher wind speeds was observed in this region during the last half of the 20th century, while wind speeds in central/southern Europe decreased slightly (Yan et al. 2002, Pryor \& Barthelmie 2003, Pryor et al. 2005b). These changes in nearsurface winds are demonstrably linked to the increased prevalence of positive phase North Atlantic Oscillation, are in accord with studies of storm frequencies in the north Atlantic (Weisse et al. 2005), and were more pronounced in winter.

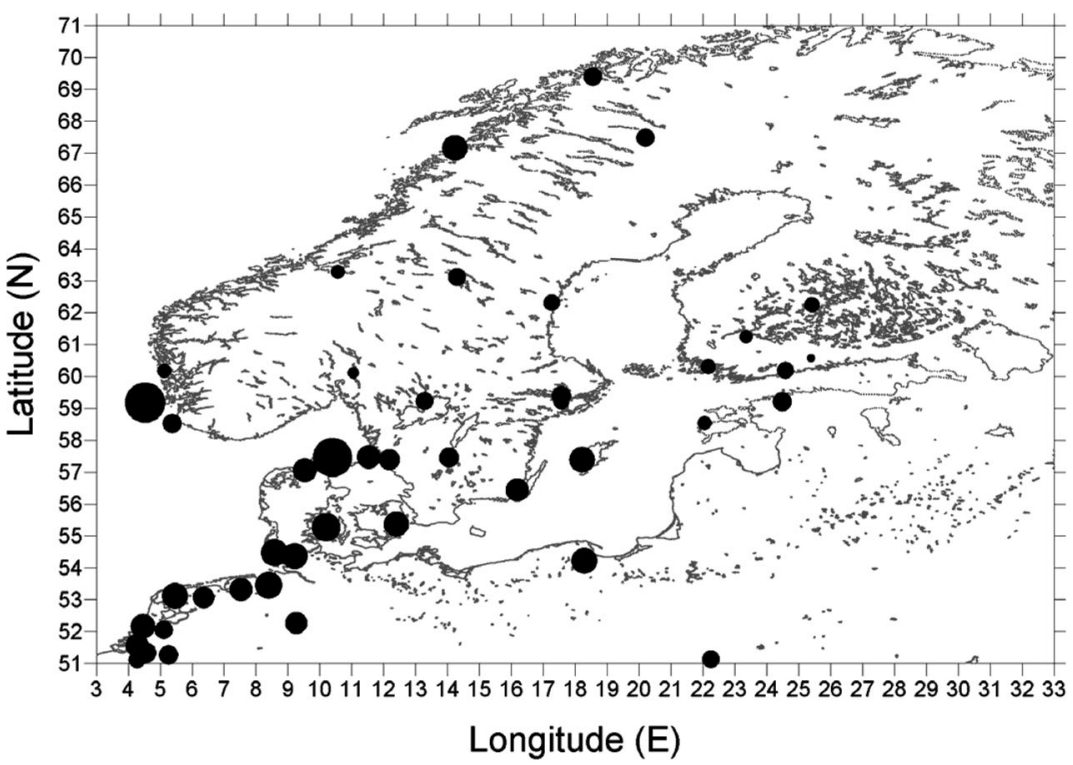

Fig. 1. Map of the study domain and location of the stations used herein. The diameter of the dots is linearly related to the magnitude of the mean observed wind speed during 1982-2002

\subsection{Data sets}

2.2.1. AOGCMs. We employ daily sealevel pressure and $500 \mathrm{hPa}$ zonal and meridional wind speed components from 5 AOGCMs (Table 1), to derive the downscaling predictor variables. For each model, we use data from 2 experiments: Climate of the 20th Century (C20th, i.e. historical forcing) and IPCC SRES A2 (IPCC 2000). Within these 2 experiments we use 3 time periods: 1961-2000 (C20th), 2046-2065 (SRES A2) and 2081-2100 (SRES A2).

2.2.2. ECMWF reanalysis (ECMWF). Daily sea-level pressure and $500 \mathrm{hPa}$ zonal and meridional wind speed components from the ECMWF reanalysis (Table 1) are used here principally to evaluate simulation of the predictor variables by the AOGCMs. The ECMWF reanalysis was selected for this purpose partly because it has recently 
Table 1. Summary of the data sets and AOGCM outputs used in the downscaling

\begin{tabular}{|c|c|c|c|c|c|c|}
\hline Name & $\begin{array}{l}\text { Abbrevia- } \\
\text { tion }\end{array}$ & Institute & $\begin{array}{l}\text { Model time } \\
\text { characteristics }\end{array}$ & $\begin{array}{l}\text { Resolution } \\
\text { (latitude } \times \\
\text { longitude) }\end{array}$ & $\begin{array}{l}\text { Atmospheric } \\
\text { model } \\
\text { characteristics }\end{array}$ & Source \\
\hline ECMWF reanalysis & ECMWF & $\begin{array}{l}\text { European Center } \\
\text { for Medium } \\
\text { Range Weather } \\
\text { Forecasts, UK }\end{array}$ & $\begin{array}{l}365 \text { day year }+ \\
\text { leap years }\end{array}$ & $2.5 \times 2.5^{\circ}$ & Spectral & Simmons \& Gibson (2000) \\
\hline $\begin{array}{l}\text { AOGCMs } \\
\text { GFDL CM2.0 }\end{array}$ & GFDL & $\begin{array}{l}\text { Geophysical Fluid } \\
\text { Dynamics } \\
\text { Laboratory, } \\
\text { NOAA, USA }\end{array}$ & 365 day year & $2 \times 2.5^{\circ}$ & $\begin{array}{l}\text { Cartesian. No } \\
\text { flux adjustment }\end{array}$ & $\begin{array}{l}\text { Global Atmospheric } \\
\text { Model Development } \\
\text { Team (2004), } \\
\text { Delworth et al. (2005) }\end{array}$ \\
\hline GISS ModelE-R & GISS & $\begin{array}{l}\text { Goddard Institute } \\
\text { for Space Science, } \\
\text { NASA, USA }\end{array}$ & 365 day year & $4 \times 5^{\circ}$ & $\begin{array}{l}\text { Cartesian. No } \\
\text { flux adjustment }\end{array}$ & Schmidt et al. (2005) \\
\hline IPSL CM4 V1 & IPSL & $\begin{array}{l}\text { Institute Pierre } \\
\text { Simon LaPlace, } \\
\text { France }\end{array}$ & 360 day year & $\begin{array}{l}2.5352 \times \\
3.75^{\circ}\end{array}$ & $\begin{array}{l}\text { Cartesian. No } \\
\text { flux adjustment }\end{array}$ & $\begin{array}{l}\text { http://mc2.ipsl.jussieu. } \\
\text { fr/simules.html, } \\
\text { http://igcmg.ipsl. } \\
\text { jussieu.fr/Doc/IPSLCM4/ }\end{array}$ \\
\hline $\begin{array}{l}\text { MIROC } 3.2 \text { medium } \\
\text { resolution }\end{array}$ & MIROC & $\begin{array}{l}\text { Center for Climate } \\
\text { System Research, } \\
\text { University of Tokyo, } \\
\text { Frontier Research } \\
\text { Center for Global } \\
\text { Change, Japan }\end{array}$ & $\begin{array}{l}365 \text { day year } \\
\text { + leap years }\end{array}$ & $\begin{array}{l}2.8125 \times \\
2.8125^{\circ}\end{array}$ & $\begin{array}{l}\text { Spectral. No } \\
\text { flux adjustment }\end{array}$ & $\begin{array}{l}\text { Numaguti et al. (1997) } \\
\text { www.ccsr.u-tokyo. } \\
\text { ac.jp/kyosei/hasumi/ } \\
\text { MIROC/tech-repo.pdf }\end{array}$ \\
\hline MRI_CGCM2.3.2a & MRI & $\begin{array}{l}\text { Meteorological } \\
\text { Research } \\
\text { Institute of Japan }\end{array}$ & 365 day year & $\begin{array}{l}2.8125 \times \\
2.8125^{\circ}\end{array}$ & $\begin{array}{l}\text { Spectral. Flux ad- } \\
\text { justments used be- } \\
\text { tween } 12^{\circ} \mathrm{S} \& 12^{\circ} \mathrm{N}\end{array}$ & $\begin{array}{l}\text { Yukimoto et al. (2001) } \\
\text { Yukimoto \& Noda (2002) }\end{array}$ \\
\hline
\end{tabular}

been demonstrated to produce a more comprehensive climatology of North Atlantic cyclones at all scales than the NCEP/NCAR reanalysis data (Hanson et al. 2004).

2.2.3. Near-surface wind speeds. Near-surface wind speeds at 46 stations that conform to a Weibull distribution provide the focus of the downscaling, and are those used in Pryor et al. (2005c). They are drawn from 2 sources: (1) International Surface Weather Observations (1982-1997), and (2) Integrated Surface Hourly Observations (1995-2002) (Lott et al. 2001). These data sets are available from NCDC (www.ncdc.noaa.gov/ oa/ncdc.html).

Time series of the hourly average 12 GMT observations of wind speed were extracted from stations within the study region (Fig. 1) for the period 1982-2000. For comparability with our previous research we interpolated the wind speeds from measurement height to $10 \mathrm{~m}$ using the power law with an exponent of 1/7 (Hsu 1988).

\section{METHODOLOGY}

Within our downscaling approach the wind speed probability distribution is represented using the 2 parameter Weibull probability density function (Johnson et al. 1995):

$$
p(U) \equiv \frac{k}{A}\left(\frac{U}{A}\right)^{k-1} \exp \left[-\left(\frac{U}{A}\right)^{k}\right] \text { for } U \geq 0, A>0, k>0
$$

where $k$ is a dimensionless shape parameter (a measure of the peakedness of the distribution), $A$ is the scale parameter (a measure of the central tendency), $U$ is the time series of wind speed observations, and $p(U)$ is the probability density function.

The $A$ and $k$ parameters can be used to compute an 'expected' energy density:

$$
E=\frac{1}{2} \rho A^{3} \Gamma\left(1+\frac{3}{k}\right)
$$

where $\Gamma$ is the gamma function $\left(\Gamma(z)=\int_{0}^{\infty} t^{z-1} \mathrm{e}^{-t} \mathrm{~d} t\right)$ and $\rho$ is air density.

The Weibull distribution parameters can be derived from, or used to derive, other descriptors of the probability distribution as follows:

$$
\begin{gathered}
\bar{U}=A \Gamma\left(1+\frac{1}{k}\right) \\
U_{X \cdot 100}=A[-1 \times \ln (1-X)]^{1 / k} \\
U_{50 \%}=A(\ln )^{1 / k}
\end{gathered}
$$


(a)

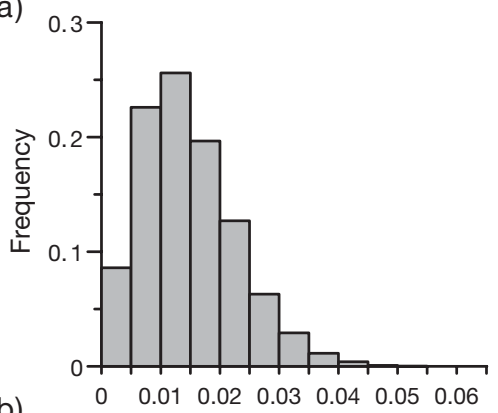

(b)

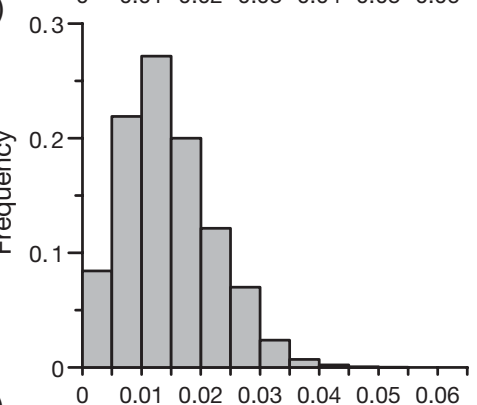

(c)

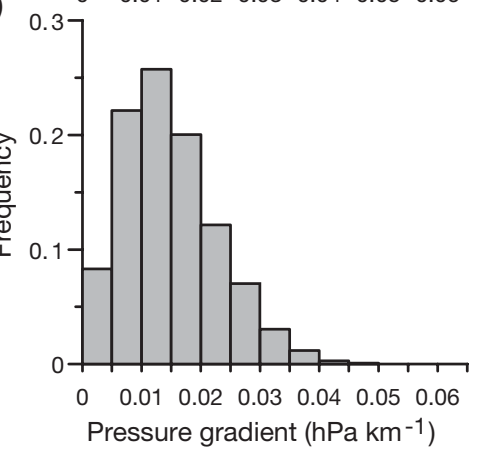

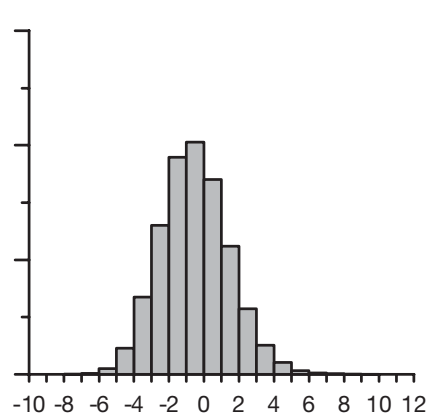
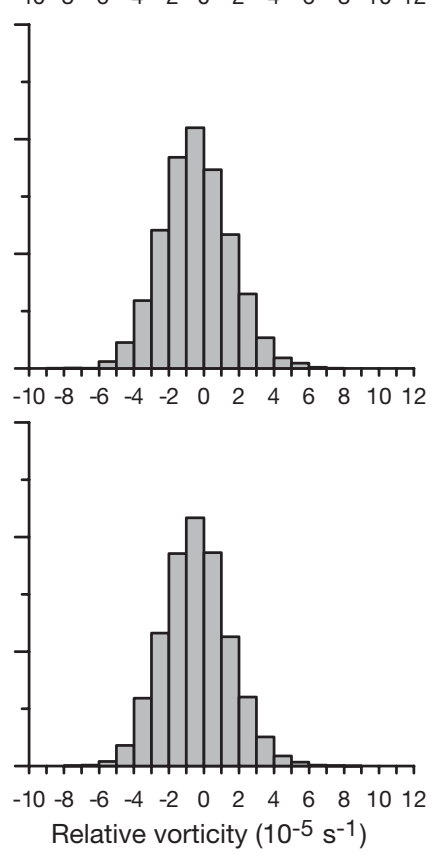

Fig. 2. Daily sea-level pressure gradient and relative vorticity from the GFDL model output for the grid cell containing Copenhagen for (a) 1961-1990, (b) 2046-2065 and (c) 2081-2100

where $\bar{U}$ is the mean wind speed, $U_{x \cdot 100}$ is the $(X \cdot 100)$ th percentile wind speed and $U_{50 \%}$ is the median wind speed.

The large-scale predictors used in the empirical downscaling are moments of the probability distributions of relative vorticity $(\zeta)$ and sea-level pressure gradient (PG). These variables are computed as follows:

- $\zeta$ is computed at $500 \mathrm{hPa}$ based on the archived $u$ - and $v$-components of the wind speed fields $\left(\zeta=\frac{\mathrm{d} v}{\mathrm{~d} x}-\frac{\mathrm{d} u}{\mathrm{~d} y}\right)$. Vorticity is used as a metric of the degree of vertical motion at the synoptic scale and hence momentum transfer from aloft.

- PG (computed as the maximum between adjacent AOGCM grid points in any of 8 directions) are computed from sea-level reduced pressure fields. Pressure gradients were selected to represent the nearsurface regional forcing of winds.
A fundamental component of empirical downscaling is the presumption of stationarity in the functional relationships between the predictor/s and predictand/s. This assumption similarly applies to the functional relationships within parameterizations used in dynamical downscaling approaches (Wilby et al. 2004). It is likely that the parameters used herein are relatively robust to the assumption of stationarity given that the linkages between the predictors and predictands are dynamic rather than thermodynamic and hence are relatively insensitive to changes in, for example, soil moisture content that may exhibit substantial changes in the future (Pan et al. 2004, Brabson et al. 2005). Further, it is rather unlikely that the predictors will exhibit 'no analogue' conditions in the future since, for example, the magnitude of relative vorticity is physically bounded by the instability of negative absolute vorticity. The probability distributions of relative vorticity and sea-level pressure gradients exhibit only modest changes in the climate projections from the 5 AOGCMs used here (example in Fig. 2). Vorticity closely approximates a Gaussian distribution, supporting the use of mean and standard deviation of this parameter in the downscaling, while the probability distribution of the pressure gradients is highly skewed, hence only the mean of the sea-level pressure gradient distribution is used as a predictor.

Our downscaling methodology is based on multiple linear regression, in which the monthly station-specific Weibull parameters (computed from the observed data: 19822000) are the predictands and the monthly mean and standard deviation of AOGCMderived relative vorticity $(\zeta)$ and the monthly mean sea-level pressure gradients (PG) are the predictors. Hence, each observation of, for example, relative vorticity during any January day in the conditioning period is used to calculate the probability distribution from which the mean and standard deviation are computed. This procedure is then repeated for every other calendar month to generate a sample of 12 values for each of the parameters (one for each month) that are used to derive a regression equation for each of the Weibull parameters:

$$
\begin{aligned}
& A_{i}=c_{1} \cdot \overline{\mathrm{PG}_{j}}+c_{2} \cdot \overline{\zeta_{j}}+c_{3} \cdot \sigma\left(\zeta_{j}\right) \\
& k_{i}=c_{4} \cdot \overline{\mathrm{PG}_{j}}+c_{5} \cdot \overline{\zeta_{j}}+c_{6} \cdot \sigma\left(\zeta_{j}\right)
\end{aligned}
$$

where $i$ is the station, $j$ is the value of the circulation parameters for the AOGCM grid cell containing the station, and $c_{1 . .6}$ are the regression coefficients. 
Table 2. Values of the downscaling predictands and predictors for the Copenhagen station in the station data and in analyses conducted using output from the GFDL AOGCM

\begin{tabular}{|lcccc|}
\hline & $\begin{array}{c}\text { Mean pressure gradient } \\
\left.(\mathrm{hPa} \mathrm{km})^{-1}\right)\end{array}$ & $\begin{array}{c}\text { Mean relative vorticity } \\
\left(10^{-5} \mathrm{~s}^{-1}\right)\end{array}$ & $\begin{array}{c}\text { SD relative vorticity } \\
\left(10^{-5} \mathrm{~s}^{-1}\right)\end{array}$ & $\begin{array}{c}\text { Weibull } A \\
\left(\mathrm{~m} \mathrm{~s}^{-1}\right)\end{array}$ \\
\hline 1982-2000: data & & & & 7.580 \\
1982-2000: downscaled & & & 2.198 \\
$1961-1990$ & $1.4707 \times 10^{-2}$ & -0.52219 & 7.9576 & 2.117 \\
$2046-2065$ & $1.4539 \times 10^{-2}$ & -0.43722 & 1.9424 & 7.588 \\
$2081-2100$ & $1.4833 \times 10^{-2}$ & -0.42789 & 1.8852 & 2.082 \\
& & & & 7.349 \\
\end{tabular}

Table 3. Regression equation coefficients for analyses for the Copenhagen station listed by predictor computed using output from the GFDL AOGCM

\begin{tabular}{|lccc|}
\hline & $\begin{array}{c}\text { Mean pressure } \\
\text { gradient }\end{array}$ & $\begin{array}{c}\text { Mean relative } \\
\text { vorticity }\end{array}$ & $\begin{array}{c}\text { SD relative } \\
\text { vorticity }\end{array}$ \\
\hline Weibull $A$ & 108.72 & -0.419076 & 2.94765 \\
Weibull $k$ & -84.8409 & -0.342785 & 1.60954 \\
\hline
\end{tabular}

Use of data at the monthly time scale to condition the downscaling equations allows representation of a range of realizations of all parameters, and as noted in Pryor et al. (2005c), inclusion of each the predictors increased the variance explanation for either the Weibull $A$ or $k$ parameters (examples in Tables $2 \& 3$ ). For all stations and all AOGCMs the $\mathrm{r}^{2}$ of the regression equations (Eqs. $6 \& 7$ ) for Weibull $A$ and $k$ exceeds 0.8 .

The Weibull parameters computed for each station are used in Eqs. (6) \& (7) to determine the regression coefficients for predictors derived from each AOGCM and the ECMWF reanalysis (see example in Table 3). The resulting equations are thus specific to each AOGCM and/or the ECMWF data set and are then used to derive the Weibull $A$ and $k$ parameters at each station for the following time periods: (a) 1982-2000; (b) 1961-1990; (c) 2046-2065; (d) 2081-2100. The output for the first 2 periods ( $a$ and $b$ ) are drawn from simulations of the C20th. The analysis for the 2 climate projection periods (c and d) are undertaken using predictors from AOGCM simulations conducted using the A2 emission scenario. Dynamical downscaling for this region using the Rossby Centre Regional Climate Model (RCAO) with boundary conditions from the ECHAM4/OPYC3 AOGCM indicates wind speed increases in 2071-2100 relative to the end of the 20th century during the winter season (Räisänen et al. 2004, Pryor et al. 2005a); hence, the same analysis is also undertaken for the winter periods (December to February) of (a) to (d). The resulting downscaled Weibull parameters for each station and time period are then used to compute the mean wind speed, energy density and wind speed probability distribution.

In a modification of the technique described in Pryor et al. (2005c), we use bootstrap resampling of the time series of the predictors to assess whether the distributions of the relative vorticity and sea-level pressure gradients are influenced by stochastic effects and whether these substantially bias the downscaling of the Weibull parameters at each site.

\section{RESULTS}

\subsection{Evaluation of the AOGCM simulation of the predictor variables}

To assess the realism of the predictor variable simulation by the AOGCMs described in Section 2.2.1, Taylor diagrams (Taylor 2001) were constructed using ECMWF reanalysis data and AOGCM simulations from the late 20th century (1961-2000) for a domain of $10^{\circ} \mathrm{W}-50^{\circ} \mathrm{E}$ and $40-85^{\circ} \mathrm{N}$ (i.e. enclosing the smaller domain for which the downscaling was conducted; $3-33^{\circ} \mathrm{E}, 51-71^{\circ} \mathrm{N}$ ). For each data set, the monthly means (relative vorticity and sea-level pressure gradient) and standard deviations (relative vorticity only) of the daily grid point predictors were computed on the original model grid. For computation of the quantities needed for the Taylor diagrams, the ECMWF means and standard deviations were interpolated to the appropriate AOGCM grid using inverse distance weighted interpolation.

4.1.1. Relative vorticity. The Taylor diagrams for the monthly means of relative vorticity (Fig. 3) indicate that the model mean fields generally exhibit large positive correlations with the ECMWF reanalysis data and that the levels of variability in the mean fields are generally well reproduced by the coupled AOGCMs. As shown in Fig. 3, relative vorticity computed from 3 of the models (GFDL, MIROC, and MRI) exhibit monthly correlations with the ECMWF reanalysis data which range from 0.35 to 0.95 . For these 3 models, normalized standard deviations of the grid point values 

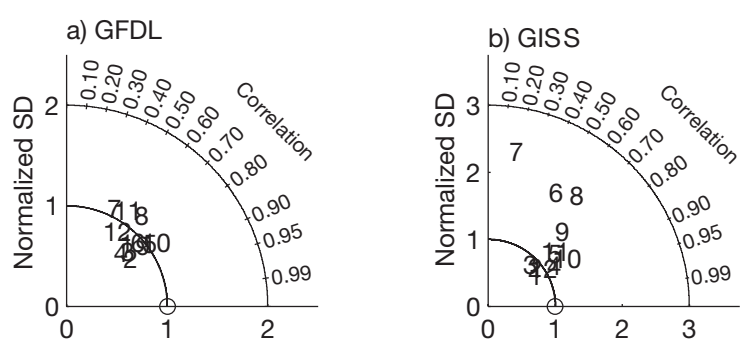

c) IPSL d) $M I R O C$
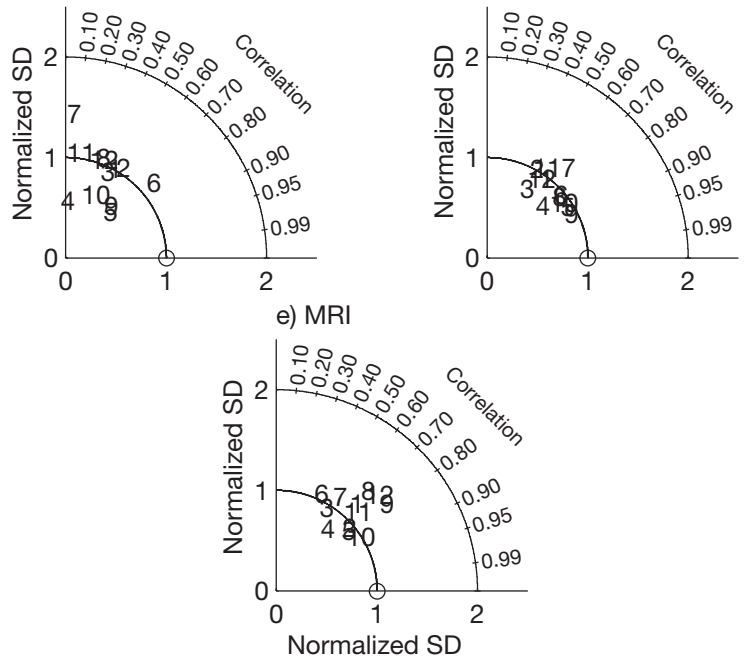

Fig. 3. Taylor diagrams for monthly mean relative vorticity (1961-2000) from the (a) GFDL, (b) GISS, (c) IPSL, (d) MIROC, and (e) MRI AOGCMs. The radial axis indicates the correlation between the observed (ECMWF) and simulated (AOGCM) fields. Horizontal and vertical axes represent the normalized standard deviation (i.e. the standard deviation of values comprising the modeled field divided by the standard deviation of the values comprising the observed field). The distance between the origin (0) and any point is proportional to the root mean squared difference. Each number indicates a month (e.g. 1 is January, 2 is February, and so on). Note that the scale on (b) differs from that of the others

comprising the mean fields are within $30 \%$ of those from the ECMWF reanalysis. For the remaining 2 models (GISS and IPSL), the monthly mean relative vorticity patterns exhibit substantial differences from the ECMWF reanalysis relative vorticity field and the resulting correlations are much lower (as low as 0.14 and -0.08 for individual months from the GISS and IPSL models, respectively). These models also exhibit weaker agreement with ECMWF reanalysis data in terms of the spatial variability in the monthly mean relative vorticity fields. This is particularly true for the GISS model, for which the standard deviation of values comprising the AOGCM-simulated mean relative vorticity field is twice as large as that for the ECMWF reanalysis during the summer months. This discrepancy may be due in part to interpolation of the ECMWF data onto the coarse grid of the GISS model.
Although the correlations between AOGCM-simulated and ECMWF-derived fields of the standard deviation of relative vorticity are high $(>0.64$ in all months, excepting MIROC $;$ Fig. 4 ), there is too little variability in the AOGCM-simulated fields relative to the ECMWF reanalysis, with the exception of the GISS model, which overestimates the variability in the field (by a factor of 2 to 3 for most months). This underestimation is most pronounced in the MIROC model (Fig. 4), for which the spatial variability in the standard deviation relative vorticity field is typically less than $50 \%$ of that found in the ECMWF reanalysis. Examination of the grid point relative vorticity standard deviations shows that the models, excepting GISS, also underestimate the magnitude of variability at the grid point level. For 4 of the models (GFDL, IPSL, MIROC, and MRI), standard deviations of relative vorticity are lower than those in the ECMWF reanalysis at every grid point during every month.

4.1.2. Sea-level pressure gradient. Agreement between AOGCM-simulated and ECMWF monthly mean sea-level pressure gradients is superior to that for relative vorticity for each AOGCM considered (Fig. 5).

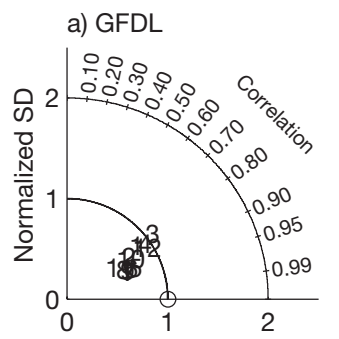

c) IPSL

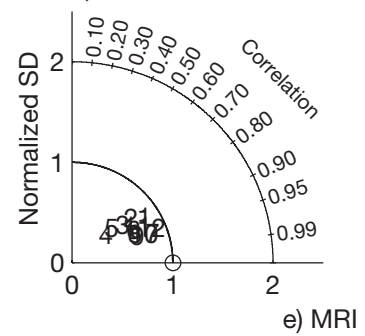

b) GISS
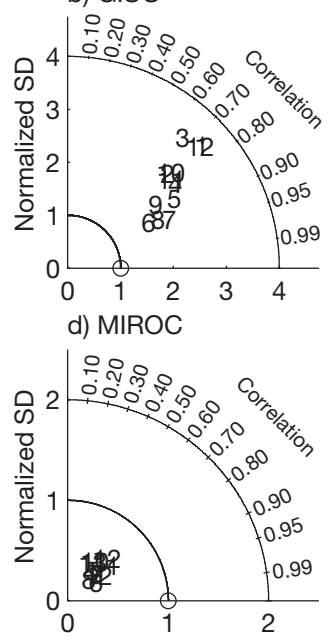

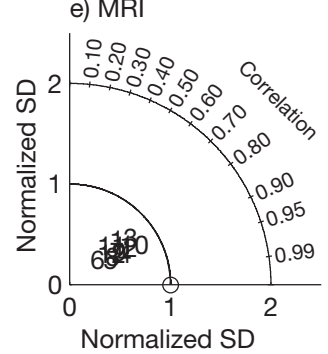

Fig. 4. Taylor diagrams for monthly standard deviation of relative vorticity (1961-2000) from the (a) GFDL, (b) GISS, (c) IPSL, (d) MIROC, and (e) MRI AOGCMs. Explanation as in Fig. 3. Note that the scale on (b) differs from that of the others 

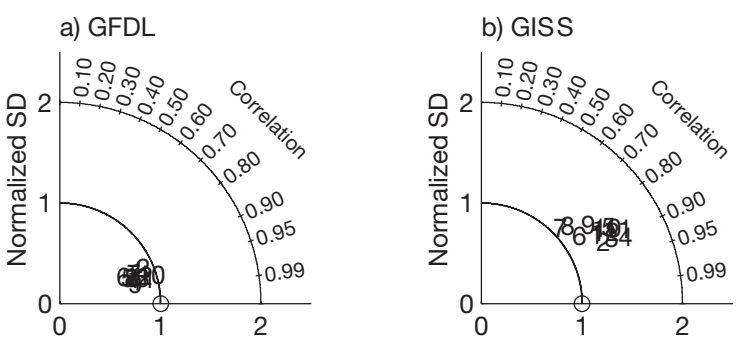

c) IPSL

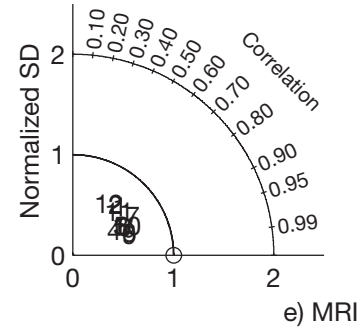

d) MIROC
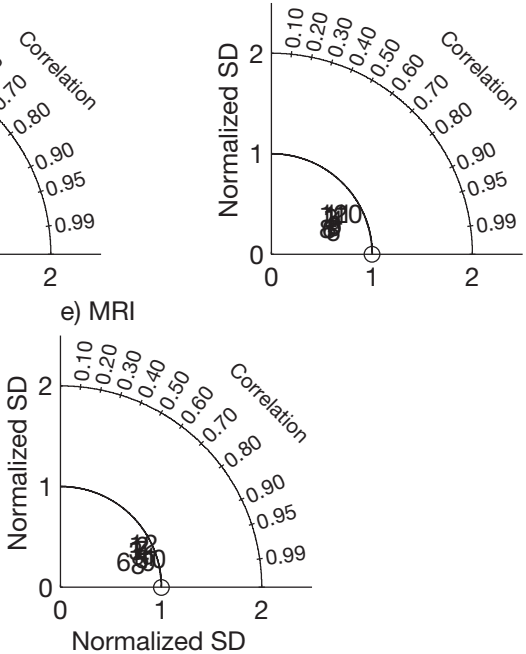

Fig. 5. Taylor diagrams for monthly mean sea-level pressure gradient (1961-2000) from the (a) GFDL, (b) GISS, (c) IPSL, (d) MIROC, and (e) MRI AOGCMs. Explanation as in Fig. 3

As with relative vorticity, simulations from GFDL, MIROC, and MRI exhibit higher correlations with ECMWF data than GISS and IPSL. For these 3 models, monthly correlations are always $>0.76$ (the correlation for each month is $>0.90$ for the GFDL model and $>0.84$ for MRI). However, as shown in Fig. 5, these 3 models underestimate the variability in the monthly mean sealevel pressure fields. Monthly correlations for the remaining 2 models, GISS and IPSL, are slightly lower (>0.68 and 0.34 for GISS and IPSL, respectively). The IPSL model additionally exhibits a substantial underestimation of the spatial variability in the mean field (model variability ranges from 40 to $60 \%$ of ECMWF variability). Unlike the other AOGCMs, the GISS model exhibits greater variability in the mean sealevel pressure gradient field relative to the ECMWF data (Fig. 5). Examination of the mean sea-level pressure gradient fields (not shown) indicates that GFDL, MIROC, and MRI fail to reproduce an area of weak sea-level pressure gradients along the southern border of the study region. Because our downscaling approach only incorporates AOGCM information from the nearest grid point to the surface station, this should not affect the models performance with respect to the empirical downscaling. The lower correlations and greater disparity between ECMWF and AOGCMsimulated variability for GISS and IPSL, however, results from (1) failure to capture the general pattern of the mean sea-level pressure gradient or (2) large differences in the variability of the values comprising the mean sea-level pressure field.

4.1.3. Summary of the evaluation of AOGCM predictors. The AOGCM evaluation results indicate that these models exhibit varying abilities to reproduce the downscaling predictors. There is no individual model that properly simulates all aspects of the 3 predictor variables (mean and standard deviation of relative vorticity and mean sea-level pressure gradient), but in general it appears that the GFDL, MIROC and MRI models most closely approximate the ECMWF fields. The discrepancies between AOGCM simulations of the predictors and the reanalysis data emphasizes the necessity of employing a Model Output Statistics (MOS) based empirical downscaling approach for this application.

\subsection{Application of the empirical downscaling approach to Copenhagen}

As an example of the implementation of the downscaling procedure, in this section we describe results from Copenhagen, Denmark. Downscaled wind speed probability distributions at Copenhagen for the 5 AOGCMs and the 3 temporal windows are slightly less peaked than those derived using ECMWF data (Fig. 6). The wind speed distribution downscaled for 1961-1990 from the ECMWF also exhibits a peak frequency at slightly higher wind speeds, which is best matched by downscaling using the MRI model output (Fig. 6), but downscaling of all models appears to reasonably simulate the characteristics of the wind speed distribution. The wind speed probability distributions derived from all the AOGCMs in the climate projection periods are relatively similar to those from 1961-1990 but, where present, differences are predominantly associated with decreasing Weibull $A$ and $k$ parameters.

Although the projected changes in Weibull $A$ and $k$ parameters are small (see for example Table 2), the associated changes in the mean wind speed, 90th percentile wind speed and energy density are not negligible (Fig. 7). The range of the 100 bootstrapped realizations of these 3 wind parameters is largest for the GISS and IPSL models. This feature is common to other grid cells and stations for which downscaling was performed. It may indicate that these models exhibit the largest temporal variability of the predictors and may be related to the finding (Section 4.1) that the GISS 

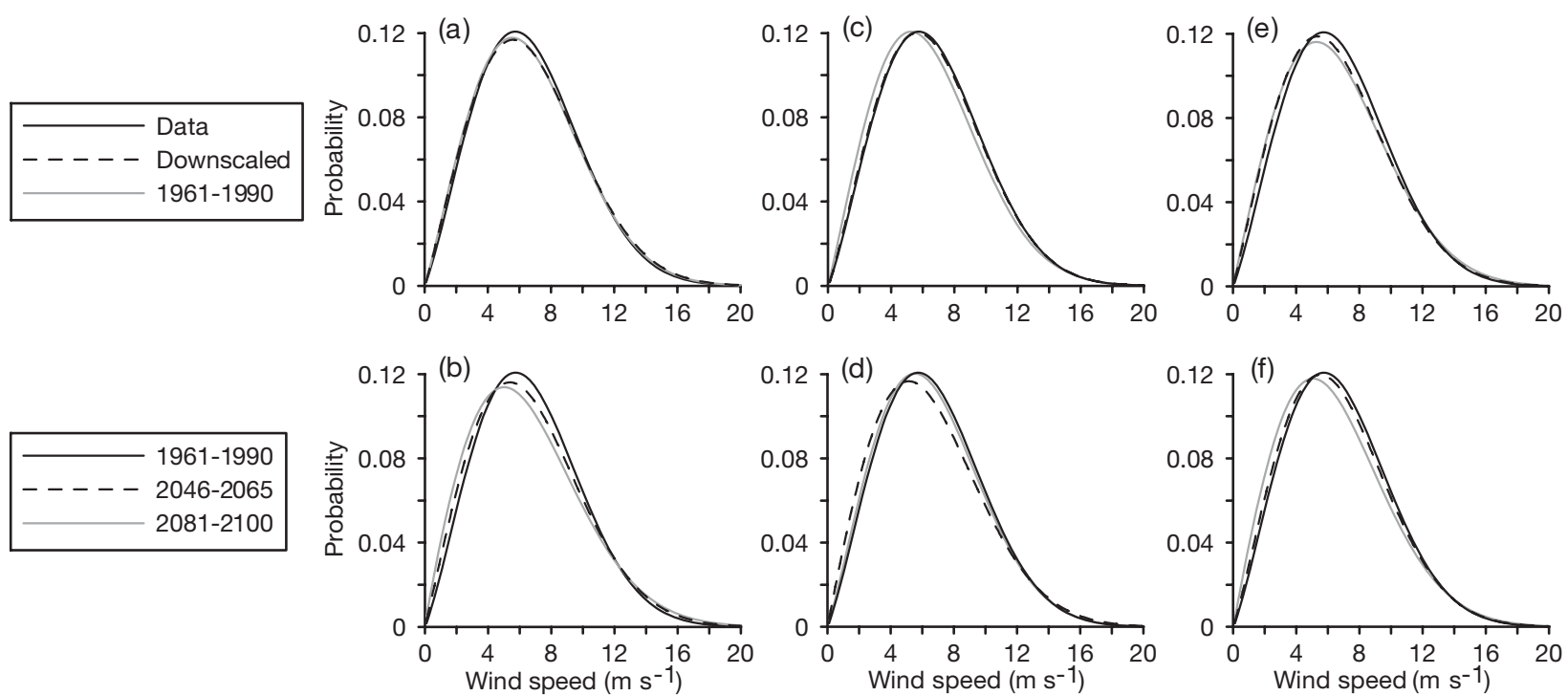

Fig. 6. Wind speed probability distributions for Copenhagen. (a) Distributions downscaled from output from the ECMWF data for 1982-2000 where the probability distribution was calculated directly from the data and downscaled from the ECMWF derived predictors from the same time period, and downscaled for 1961-1990. (b-f) Distributions for downscaling of 1961-1990, 2046-2065 and 2081-2100 using output from the (b) GFDL, (c) GISS, (d) IPSL, (e) MIROC and (f) MRI AOGCMs. Legend at the upper left applies to panel (a), while the legend at the lower left applies to panels (b) to (f)

model overestimated spatial variability of the predictors during the 1961-1990 period relative to the ECMWF reanalysis. Only downscaling using the IPSL model output indicates a change in any of the 3 wind speed parameters shown in Fig. 7 for the climate projection periods that lie beyond the entire range of the 100 bootstrapped data sets for 1961-1990. However, downscaled results for 4 of the models (GISS, IPSL, MIROC, and MRI) imply lower mean wind speed, 90th percentile wind speed and energy density in 2081-2100 than in 1961-1990. The results for 2046-2065 also indicate lower values of these parameters than in 1961-1990 but the results from the different models are less consistent.

Lower mean wind speed is not uniformly associated with lowering of the 90th percentile wind speed. Instead there is evidence in some cases for a broadening of the probability distribution and hence increased variability. For example, Fig. 7 a shows downscaling results from the GFDL model which exhibit reduction in the mean wind speed in 2081-2100 relative to 1961-1990 but an increase in 90th percentile wind speed due to the combined impact of changes in the Weibull $A$ and $k$ parameters.

The predictor responsible for the change in the Weibull parameters is variable from site to site and AOGCM to AOGCM. As shown in the example from Copenhagen (Table 2), all 3 predictors from the GFDL model differ between the control run (1961-1990) and the 2 future periods.

\subsection{Empirically downscaled wind speed parameters for 1961-1990, 2046-2065 and 2081-2100}

Fig. 8 synthesizes the downscaling results for both climate projection periods for all 46 stations using the confidence intervals for the empirically downscaled wind parameters derived using bootstrap resampling of the time series of relative vorticity and sea-level pressure gradients to generate 100 realizations of the predictors used in the regression equations of Weibull $A$ and $k$ for each site. The resulting Weibull parameters are used to generate 100 realizations of the mean and 90th percentile wind speeds and energy density. The upper 3 images in each frame show comparison of the 100 bootstrapped data sets of downscaled Weibull $A$ and $k$ as manifest in mean, 90th percentile and energy density from 2046-2065 relative to 1961-1990. The lower 3 images in each frame show the same comparison but for the 2081-2100 period relative to 1961-1990. As an example, results for downscaling of the GISS AOGCM output (Fig. 8b) indicate that at most sites the 100 bootstrapped Weibull $A$ and $k$ realizations generate mean wind speeds for 1961-1990 that exhibit substantial overlap with the 100 downscaled mean wind speeds from 2046-2065. However, the 90th value of mean wind speed from the ranked bootstrapped data set for 2081-2100 is lower than the 10th value in the ranked bootstrapped data set for 1961-1990 at over half of the stations. 
For the majority of stations the downscaled parameters using all of the AOGCMs for the climate projection periods indicate values lower than those that characterize 1961-1990. However, these changes are typically of small magnitude. For example, at the Copenhagen station, the mean wind speed is a maximum of $0.4 \mathrm{~m} \mathrm{~s}^{-1}$ lower during the 2081-2100 (rela- tive to a baseline of 6.6 to $7 \mathrm{~m} \mathrm{~s}^{-1}$ during 1961-1990), the 90th percentile wind speed is a maximum of $0.4 \mathrm{~m} \mathrm{~s}^{-1}$ lower during the 2081-2100 (relative to a baseline of 11.2 to $11.4 \mathrm{~m} \mathrm{~s}^{-1}$ during 1961-1990), and energy density is a maximum of approximately $25 \mathrm{~W}$ $\mathrm{m}^{-2}$ lower (relative to a baseline of 320 to $340 \mathrm{~W} \mathrm{~m}^{-2}$ during the 1961-1990 period) (Fig. 7). Additionally, (a)

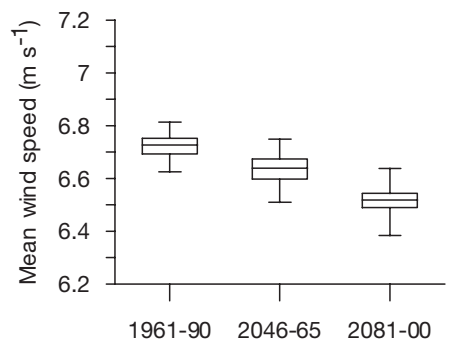

(b)

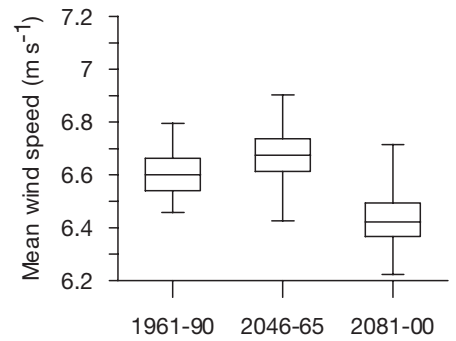

(c)

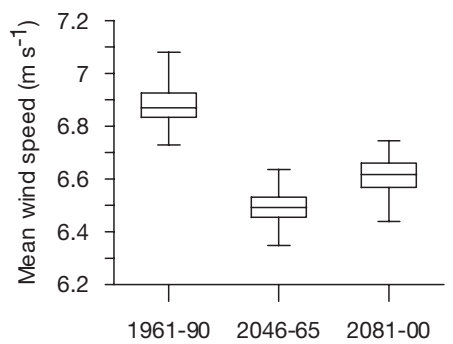

(d)
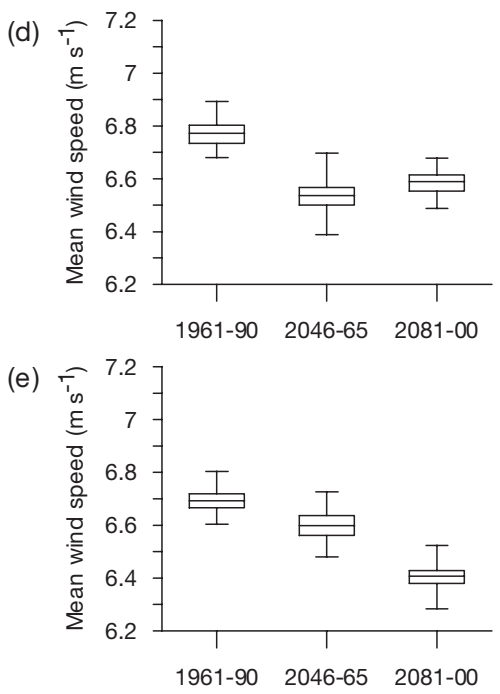
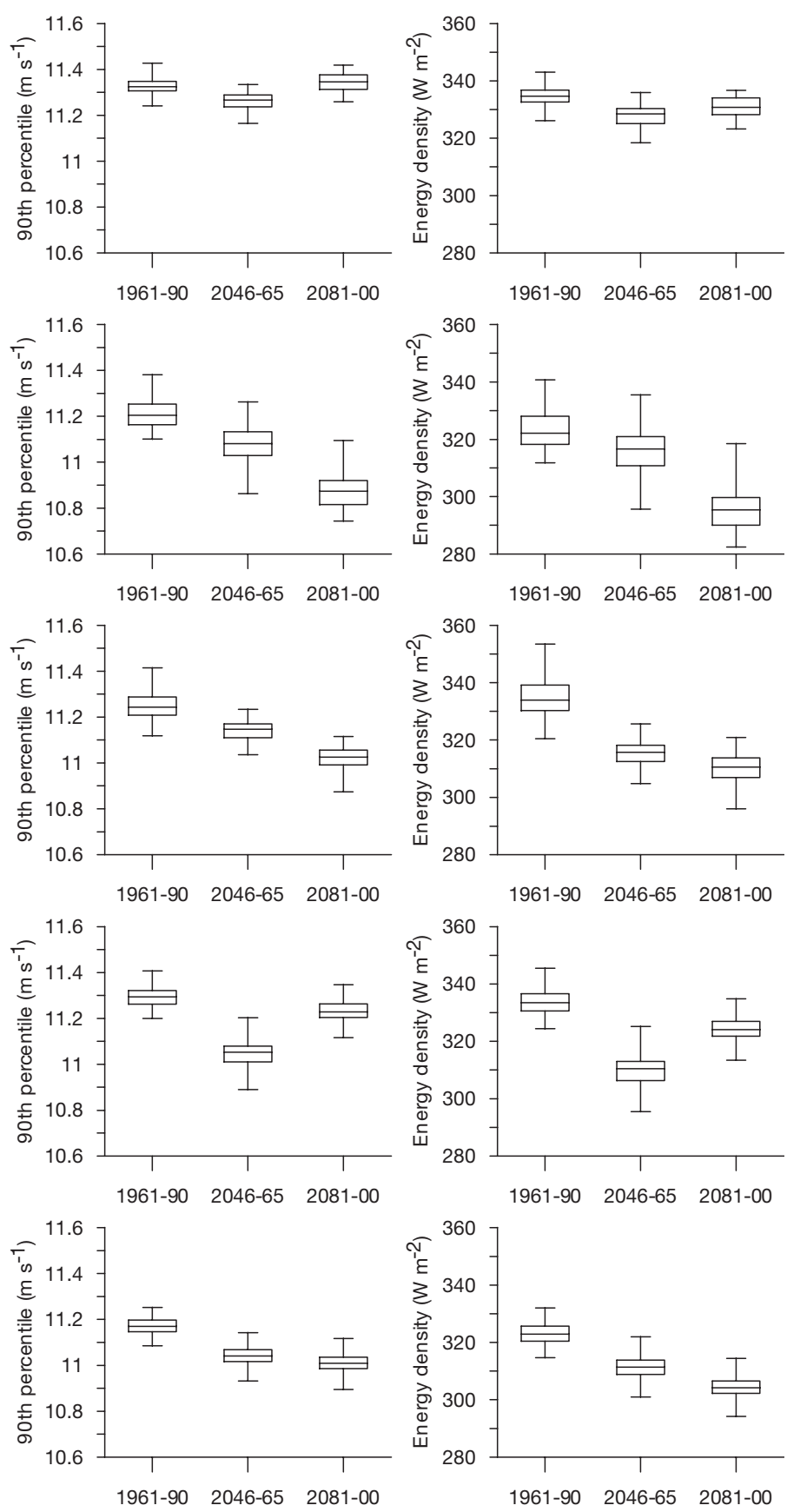

Fig. 7. Bootstrapped data sets for the Copenhagen station for 1961-1990, 2046-2065 and 2081-2100 for mean wind speed (lefthand column), 90th percentile wind speed (central column) and energy density (right-hand column) for downscaling of the 5 AOGCMs: (a) GFDL, (b) GISS, (c) IPSL, (d) MIROC and (e) MRI 
(a) GFDL Mean wind speed
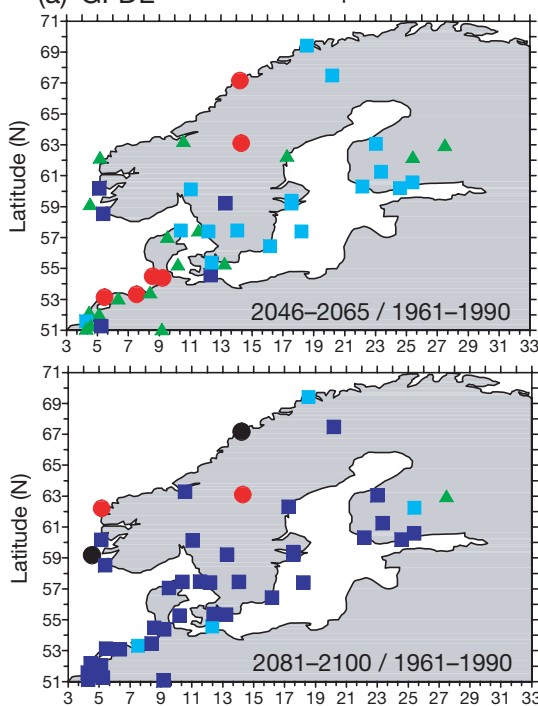

(b) GISS Mean wind speed
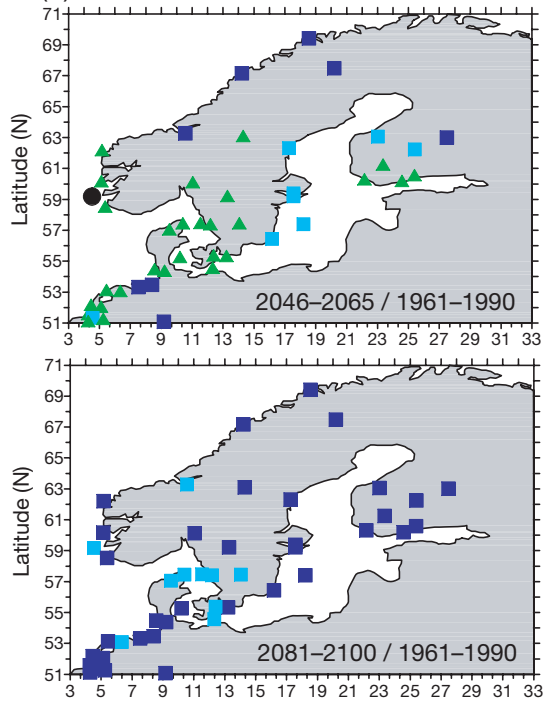

(c) IPSL Mean wind speed
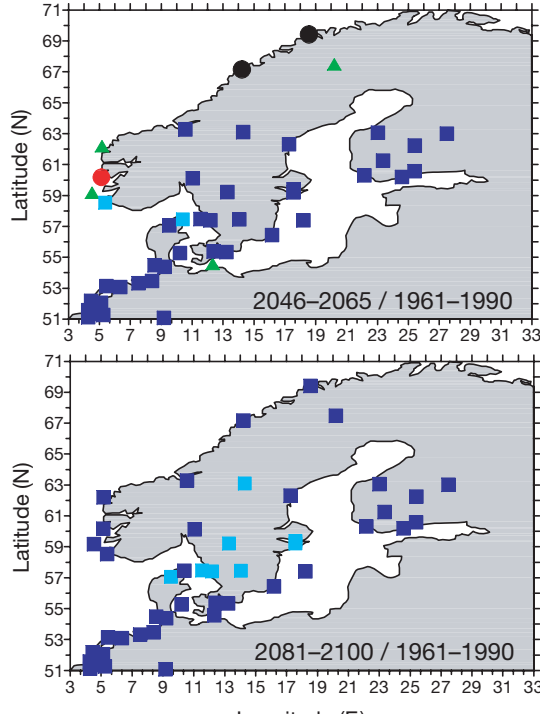

Longitude (E) 90th percentile

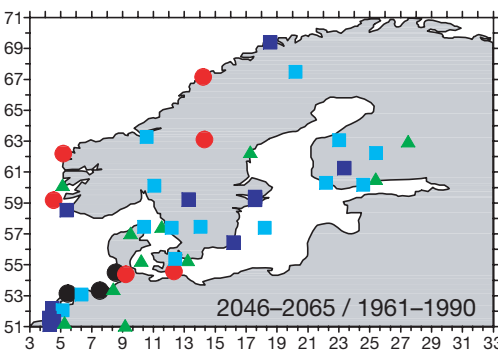

Energy density
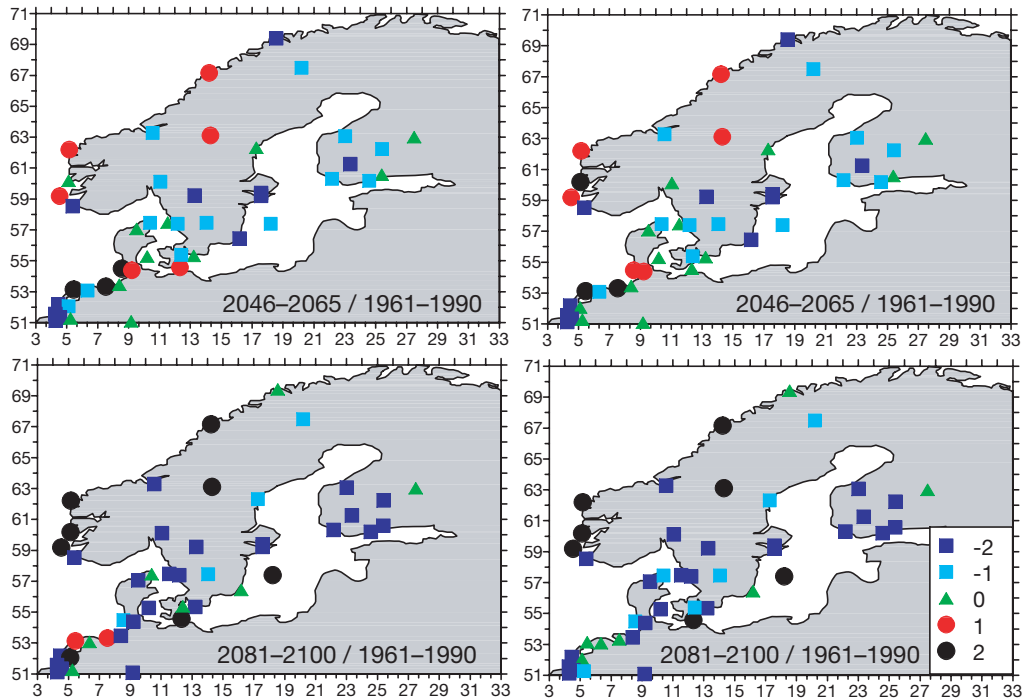

90th percentile
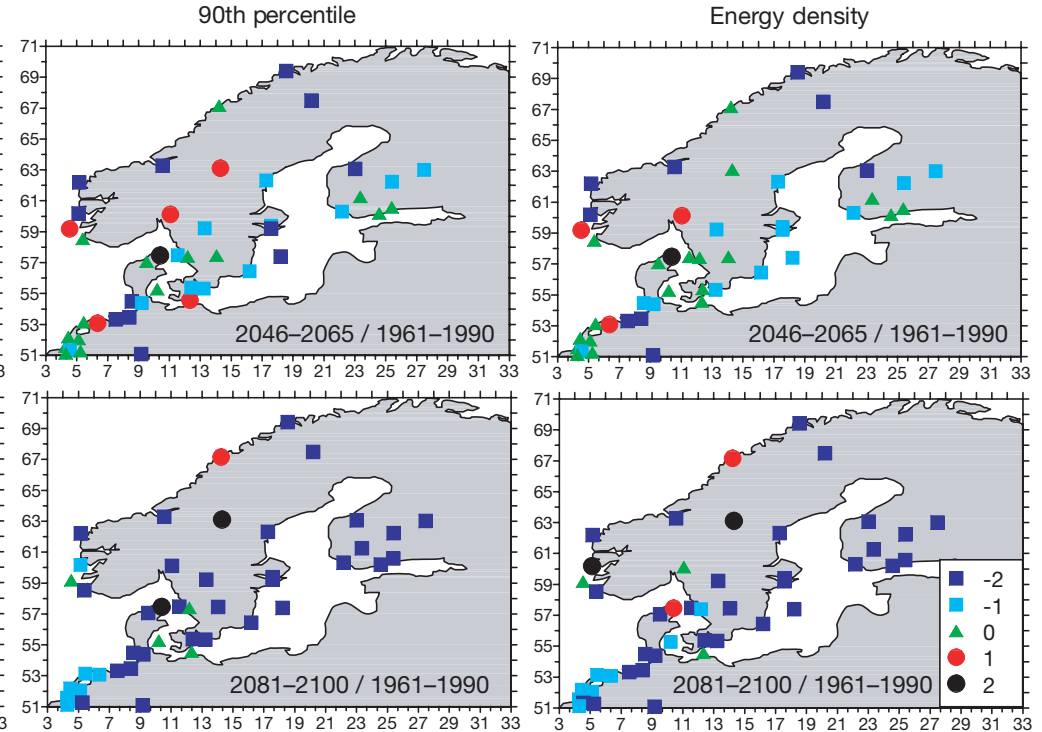

90th percentile
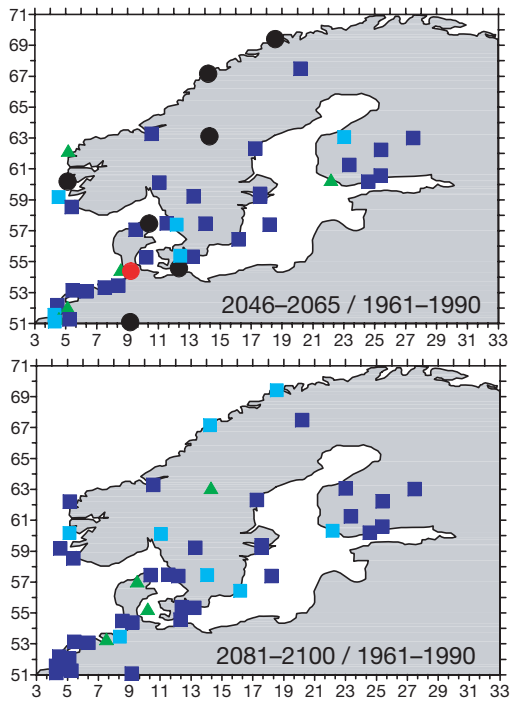

Longitude (E)

Fig. 8.
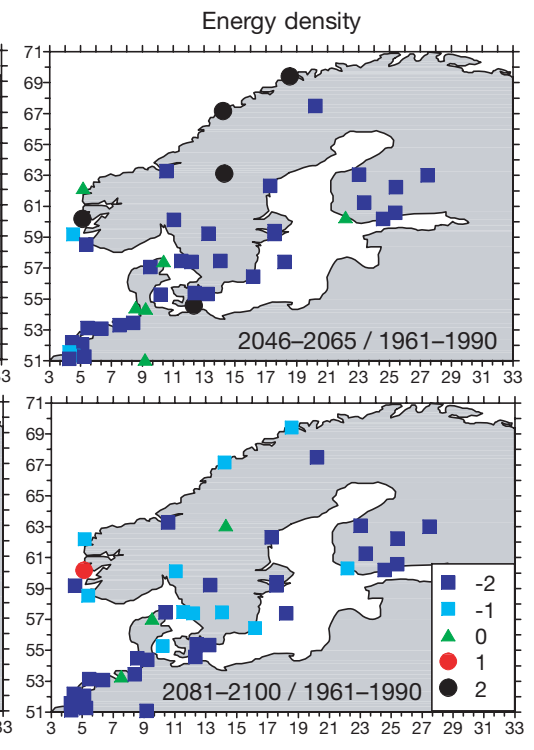

Longitude (E) 
(d) MIROC Mean wind speed
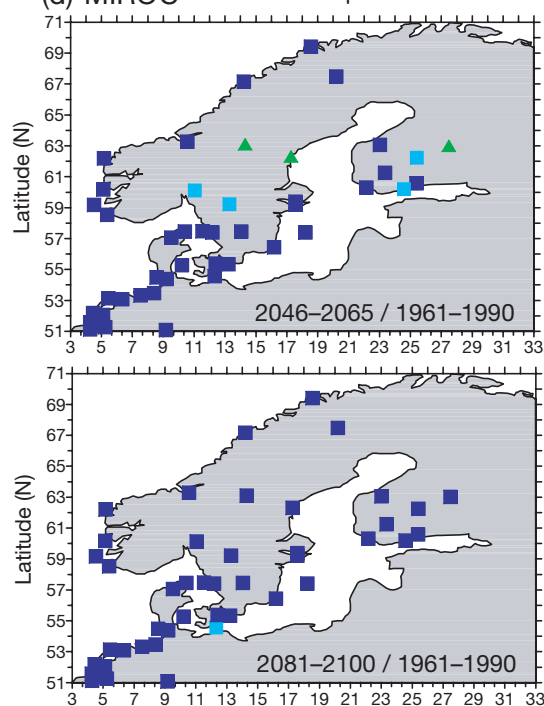

(e) MRI Mean wind speed
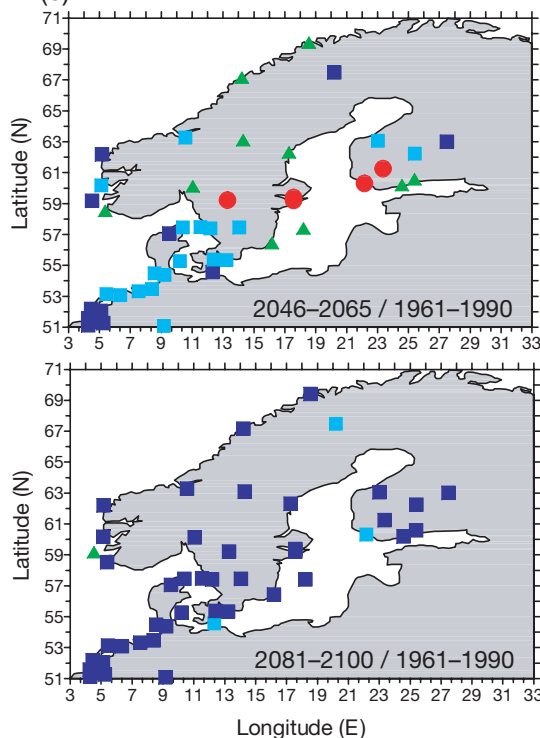

90th percentile
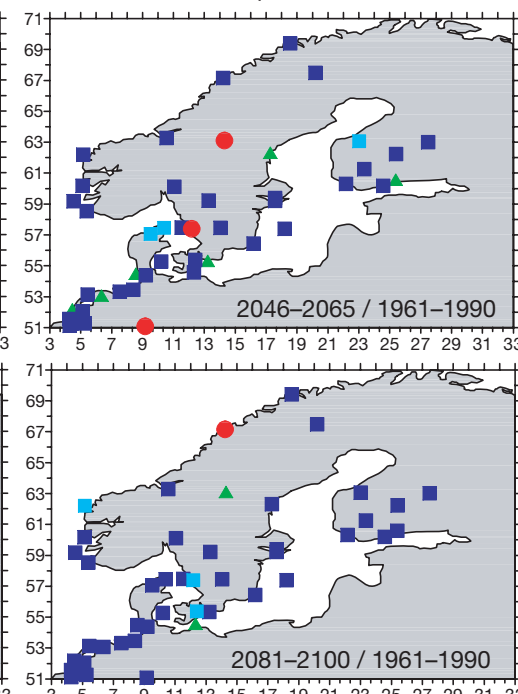

90th percentile
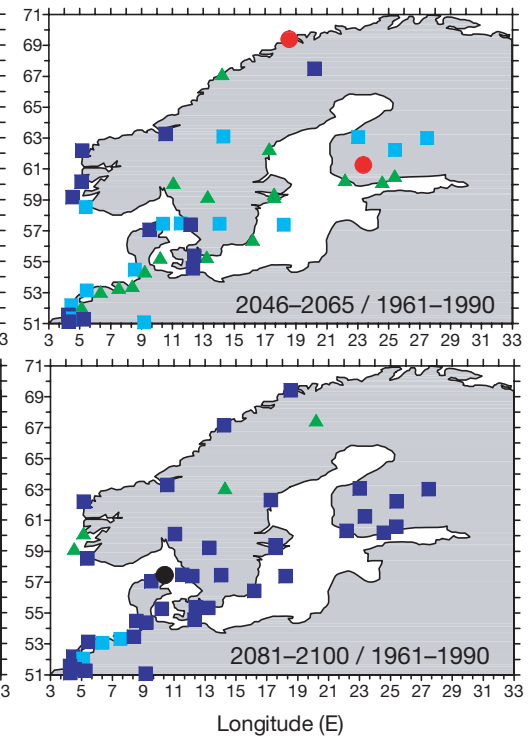

Energy density
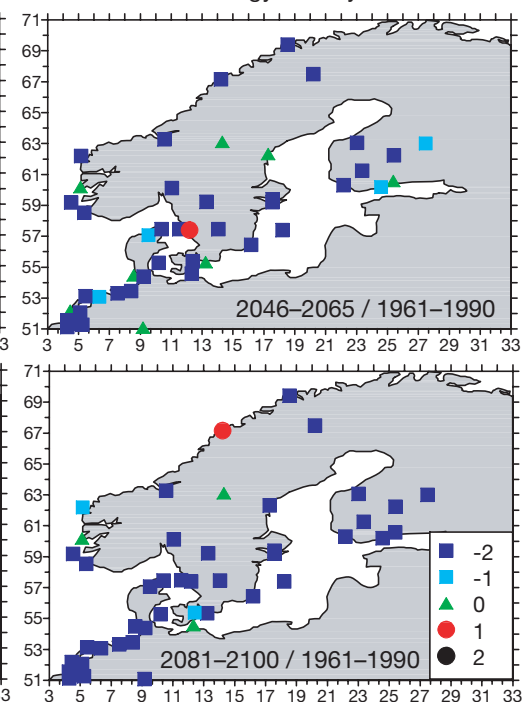

Energy density
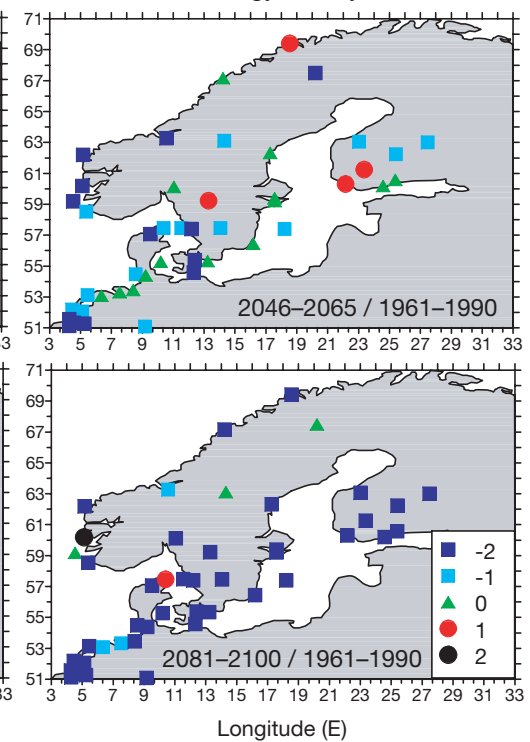

Fig. 8. (Above and opposite page.) Comparison of the 100 realizations of mean wind speed, 90th percentile wind speed and energy density from AOGCM simulations for 1961-1990 and the 2 future time periods. The scale is as follows, where $\mathrm{F}$ is the ordered 100-bootstrapped samples from the future period, and $\mathrm{C}$ is the ordered 100-bootstrapped samples from the control period (1961-1990): If -2 then 90th value in $F<10$ th value in $C_{i}$ If -1 then 50th value in $F<10$ th value in $C_{i}$ If 1 then 50 th value in $F>$ 90th value in $C_{i}$ If 2 then 10th value in $F>90$ th value in $C_{i}$ If 0 then none of the above are true (the bootstrapped data sets overlap). (a) GFDL, (b) GISS, (c) IPSL, (d) MIROC and (e) MRI. The top 3 panels for each AOGCM show the results for 2046-2065 relative to 1961-1990, the lower 3 panels show comparison of 2081-2100 with 1961-1900

there are a number of discrepancies between the AOGCMs. Downscaling conducted using the GFDL model output indicates that some stations in the southwest of the domain exhibit slight increases or no changes in 2046-2065 relative to 1961-1990 in all 3 parameters while stations across the center of the Baltic exhibit lower values in 2046-2065 than in 1961-1990. This is also true of 2081-2100 although the number of stations exhibiting lower values of mean wind speed, 90th percentile wind speed and energy density relative to 1961-1990 is higher than in 2046-2065. Many stations exhibit no change between 1961-1990 and 2046-2065 in downscaling of the GISS and MRI model outputs, but results from 2081-2100 typically exhibit declines from 1961-1990. In contrast, the downscaling results from the IPSL and MIROC output indicate that the 2046-2065 period is characterized by substantially lower values than 1961-1990 but there is little further change to 2081-2100. 
(a) GFDL Mean wind speed
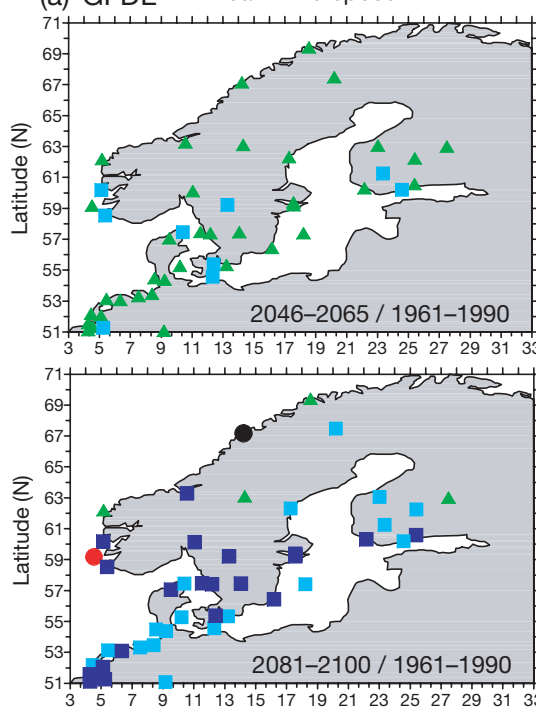

(b) GISS Mean wind speed
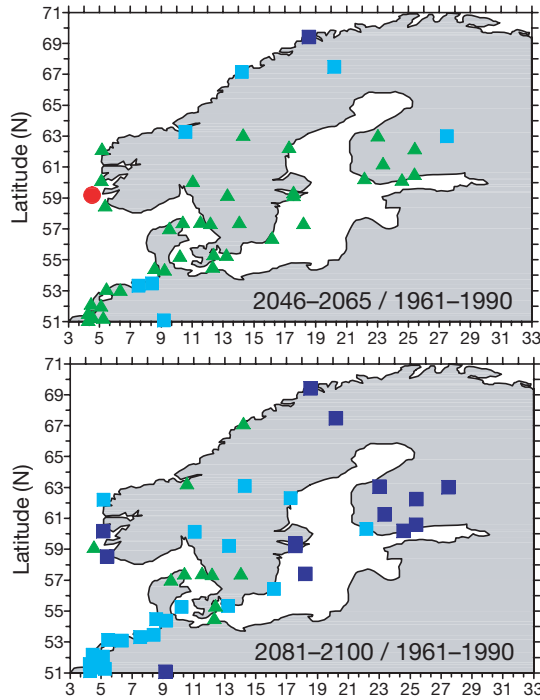

(c) IPSL Mean wind speed
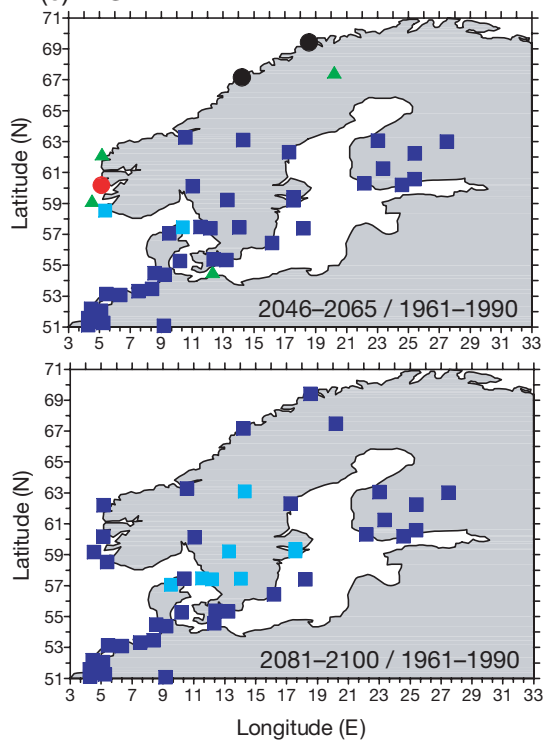

90th percentile
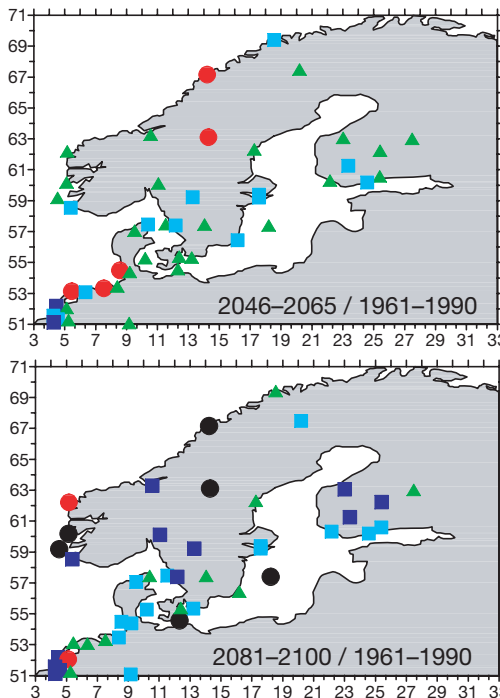

90th percentile
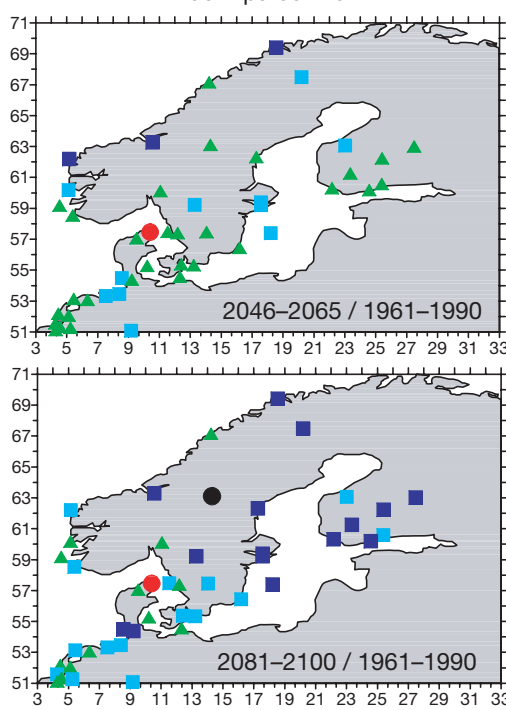

90th percentile
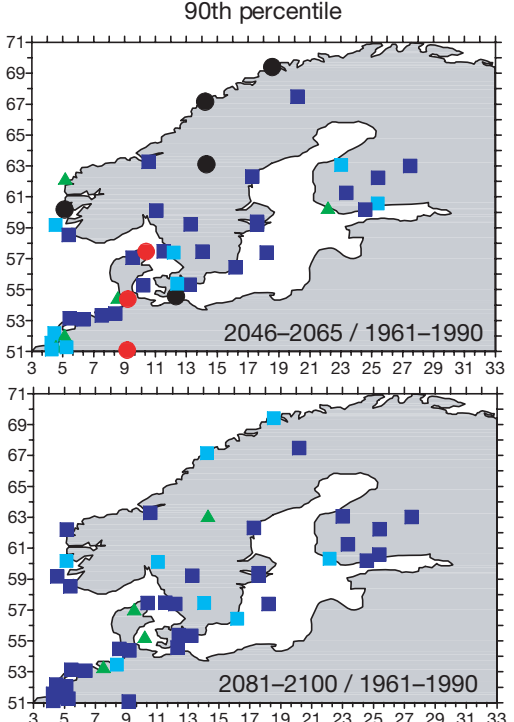

Longitude (E)

Fig. 9.

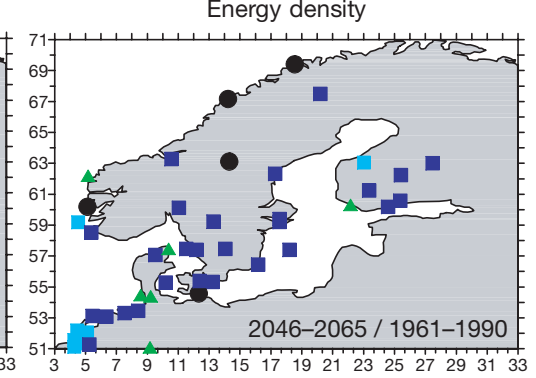

Energy density
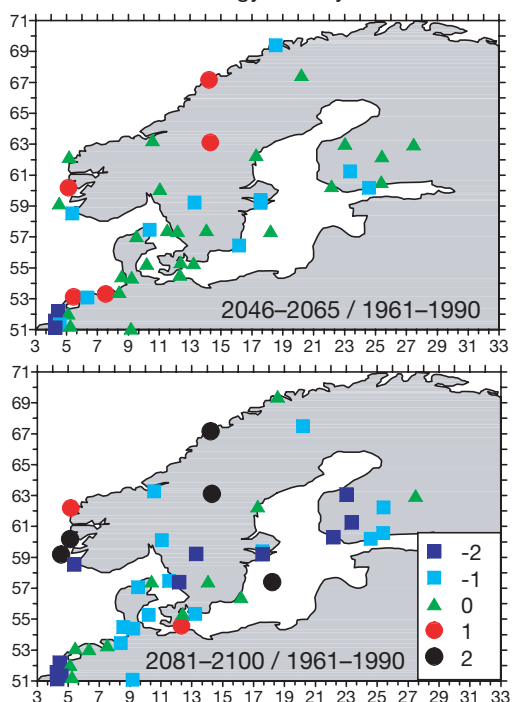

Energy density
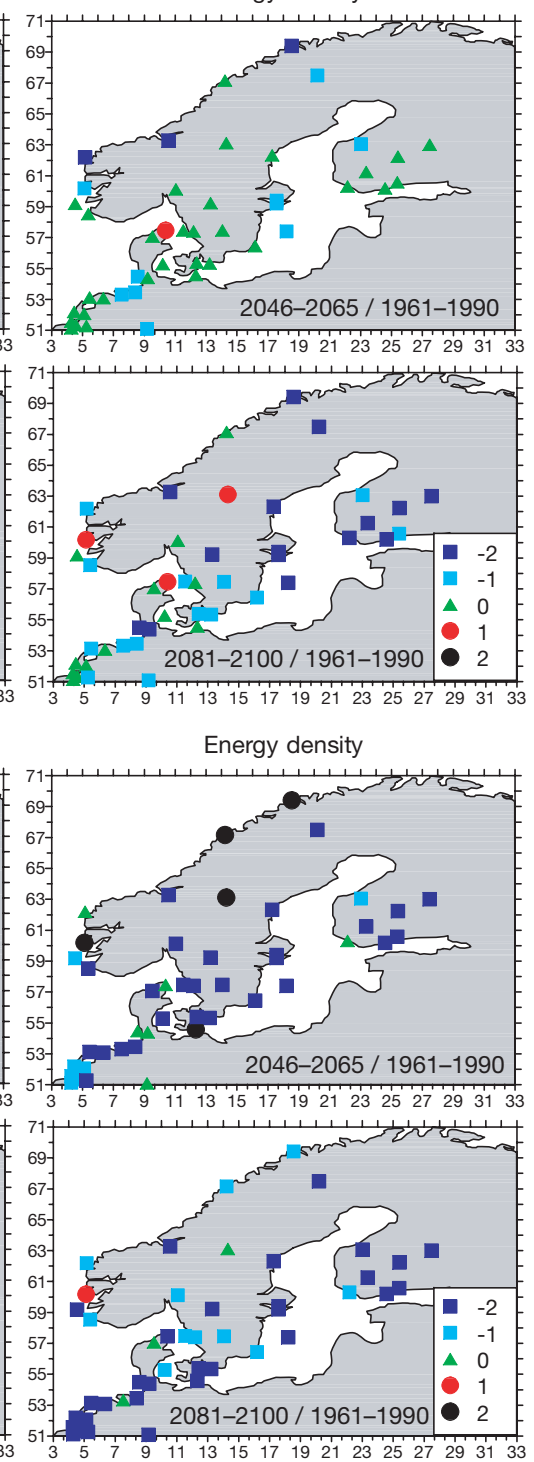

Longitude (E) 
(d) MIROC Mean wind speed
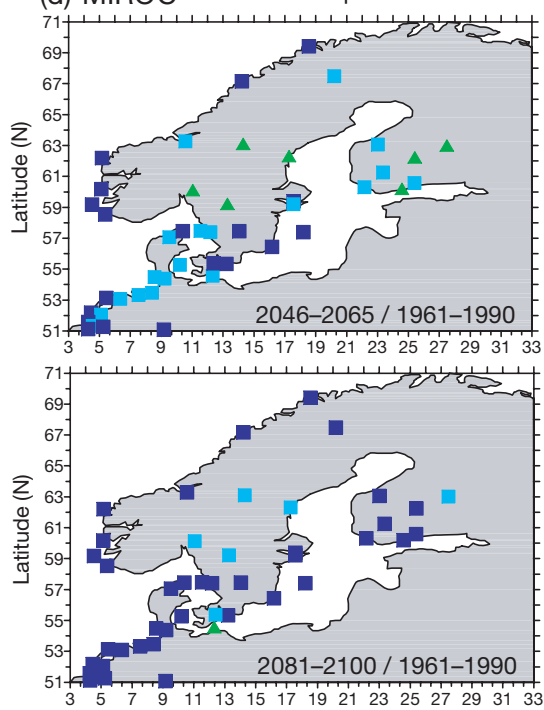

(e) MRI Mean wind speed
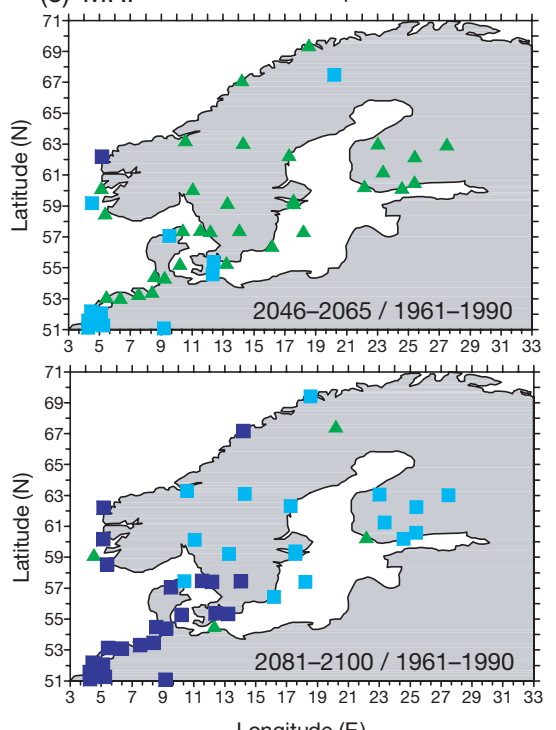

90th percentile
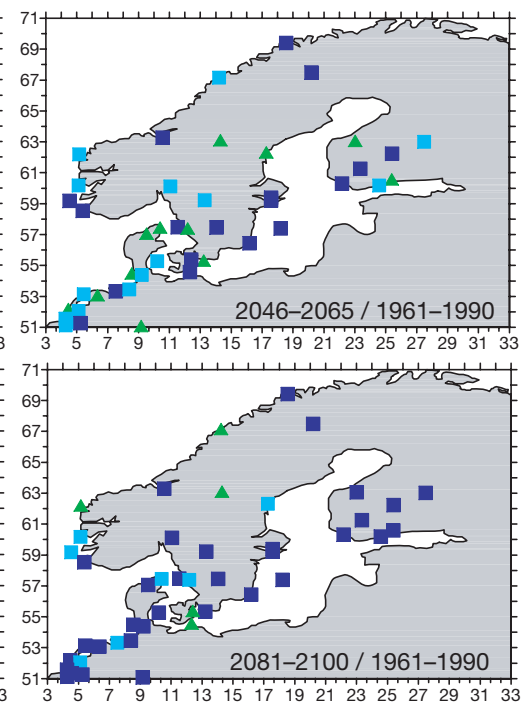

90th percentile
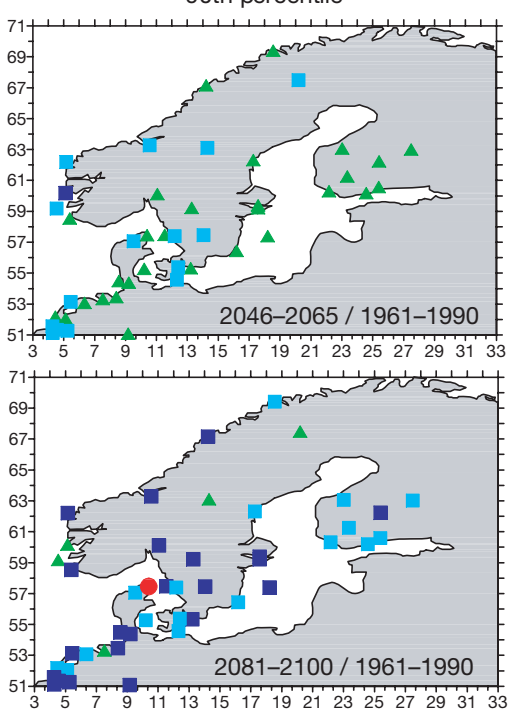

Energy density
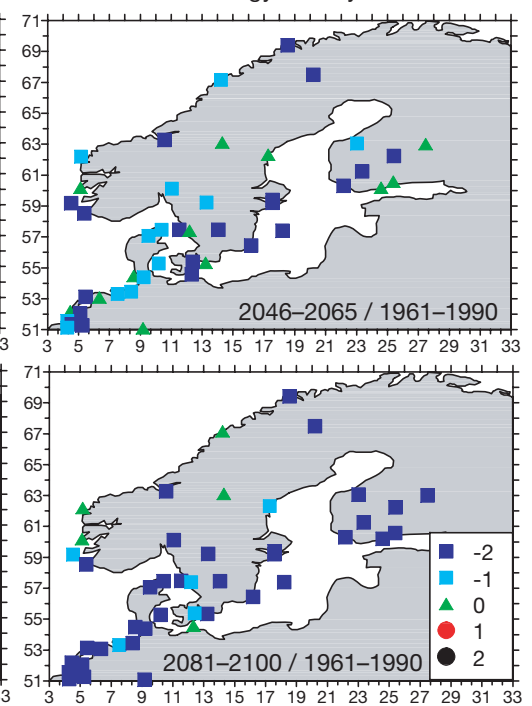

Energy density
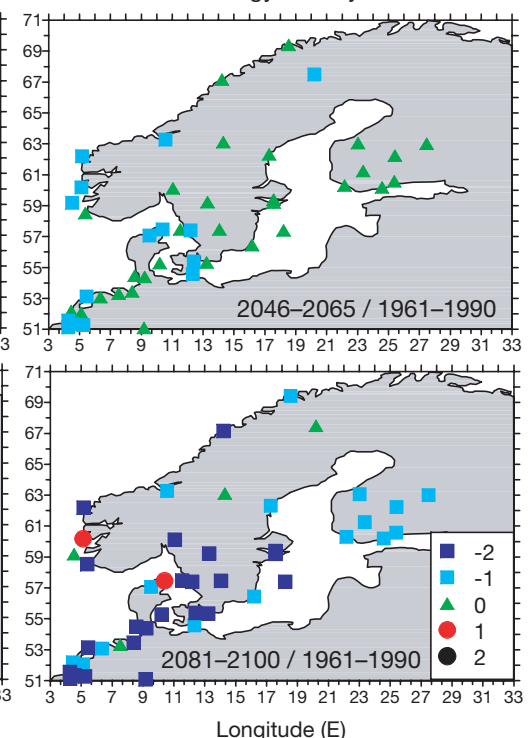

Fig. 9. (Above and opposite page.) Comparison of the 100 bootstrapped data sets from winter of 1961-1990, 2046-2065 and 2081-2100. Scale as in Fig. 8. (a) GFDL, (b) GISS, (c) IPSL, (d) MIROC and (e) MRI. The top 3 panels for each AOGCM show results from 2046-2065 relative to 1961-1990, the lower 3 panels show comparison of 2081-2100 to 1961-1900

For the winter season (Fig. 9), downscaled results using output from the GFDL, GISS and MRI models exhibit no changes between 1961-1990 and 2046-2065 while the IPSL and MIROC models suggest the future period will exhibit lower mean and 90th percentile wind speeds and energy density during the winter. The models are more consistent for 2081-2100 with downscaling to the majority of stations generating lower wind speeds and energy density in the winter than during 1961-1990. It is noteworthy that there is some evidence of differential behavior of stations in the Scandic Peninsula relative to the rest of the study region. For example, in downscaling from the GFDL
AOGCM 3 out of 4 sites in the southwest of Norway exhibit higher 90th percentile wind speeds and energy density in the winters of 2081-2100 than characterize winters during 1961-1990.

Much emphasis has been recently placed on comparing the estimate of change in a given climate parameter relative to the uncertainty in the projections arising from uncertainty in initial conditions, adopting different scenarios of future greenhouse gas concentrations, and the climate system response as manifest in multiple AOGCM formulations (Allen \& Ingram 2002, Benestad 2002, Palmer \& Räisänen 2002). Fig. 10 displays the results from empirical downscaling of the 5 AOGCMs in a 

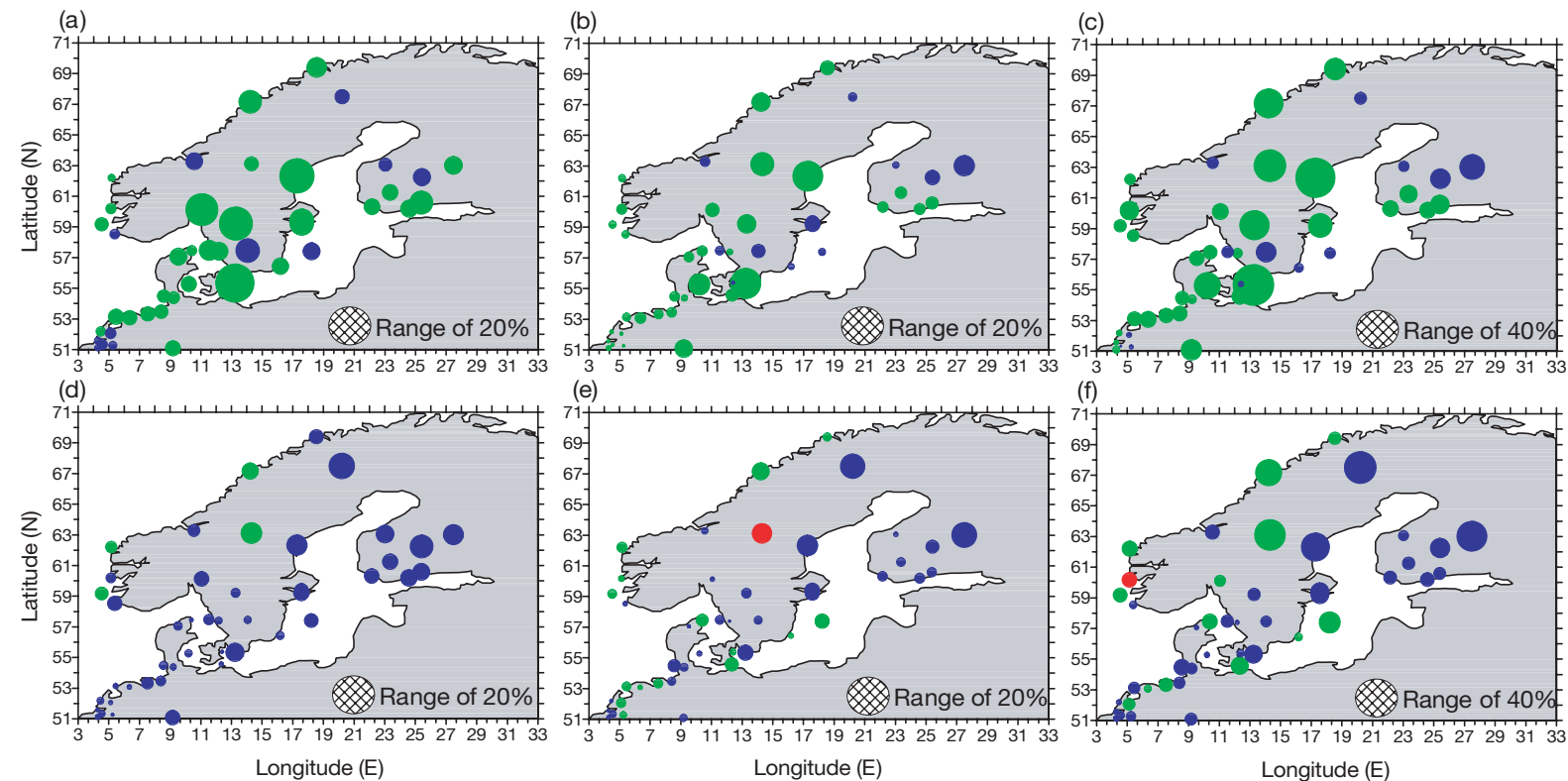

Fig. 10. Depiction of the consistency in the change of (a) mean wind speed, (b) 90th percentile wind speed and (c) energy density from the 'best guess' downscaled values at each station from the 5 AOGCMs for 2046-2065 relative to 1961-1990 (i.e. [(2046-2065) - (1961-1990))/(2046-2065)]. Blue symbols: all the downscaled values indicate declines in the specified parameter; red symbols: downscaled values from each of the 5 AOGCM indicate increases; green symbols: neither condition is satisfied. The diameter of the symbol is linearly related to the range in the relative changes from the 5 models. (d), (e) and (f) show the same information, but for downscaling conducted for 2081-2100 relative to 1961-1990

fashion that summarizes both the degree of consistency of the sign of the results (i.e. the sign of the difference between parameter estimates in the projection periods relative to the reference period; 1961-1990) and the magnitude of the range of changes calculated as the normalized change of the wind speed parameter at each station from the 5 AOGCMs. In this comparison only the 'best guess' downscaling results are used (i.e. those derived from the AOGCM predictors without application of bootstrapping) and all AOGCMs are given equal weighting. Downscaling results for the 2081-2100 climate projection period indicate generally lower mean wind speeds, 90th percentile wind speeds and energy density relative to 1961-1990 from all 5 AOGCMs at the majority of the 46 stations studied (Fig. 10). The results from the climate projection period of 2046-2065 are much more ambiguous and show much greater disparity between AOGCMs, with some models showing increased mean wind speeds at particular stations, while others show decreases. Generally it is found that there is no significant difference between conditions during 2046-2065 and 1961-1990 based on the ensemble of the model results.

\section{DISCUSSION AND CONCLUSIONS}

We present results of application of empirical downscaling tools to output from 5 state-of-the-art AOGCMs to investigate projected changes in wind speeds and energy density in northern Europe. Of the 5 AOGCMs tested the GFDL, MIROC and MRI models appear best able to reproduce the downscaling predictors (mean and standard deviation of relative vorticity at $500 \mathrm{hPa}$ and mean sea-level pressure gradients) during 1961-2000 relative to the EMCWF reanalysis data set.

Individual station locations differ both in terms of the degree of coupling to the regional scale flow (and hence the form of the transfer functions), and the projected changes in wind speed regimes. Nevertheless we demonstrate that this downscaling approach generates accurate depictions of the wind climate during the transfer function conditioning period and generally consistent results from the 5 AOGCMs. Further, our approach illuminates differential changes in the wind speed probability distribution such as a decrease in mean but an increase in the 90th percentile wind speed, which may be less well captured by time series techniques. The approach used here is, however, subject to a number of caveats. For example, there are limitations in the suitability of the Weibull distribution to wind speeds in some regimes (Takle \& Brown 1978). Additionally, long-term wind records are difficult to obtain and frequently exhibit discontinuities resulting from changes in measurement technique or height (Klink 2002). We have assumed that the records we use herein are sufficient to establish a robust wind climate for the downscaling conditioning period and have used 
data only from sites where the Weibull distribution is a good representation of observed wind speeds during the conditioning period.

Projected changes in the wind speed probability distribution are sensitive to the selection of the AOGCMs from which the predictors are derived, but generally it is shown that in the 2081-2100 climate projection period, mean wind speeds, 90th percentile wind speeds and energy density are slightly lower than during 1961-1990 at the majority of the 46 stations studied. However, there is no significant difference between conditions during 2046-2065 and 1961-1990 based on the ensemble of downscaling results. Equally, the winter time of 2046-2065 is largely indistinguishable from 1961-1990 for the majority of stations, while the winters of 2081-2100 appear to be associated with lower mean and 90th percentile wind speeds and energy density.

Pryor et al. (2005a) report higher wind speeds and energy density in northern Europe during 2071-2100 relative to 1961-1990 based on dynamical downscaling of the ECHAM4/OPYC3 AOGCM, but little or no change in RCM simulations using boundary conditions from HadAM3H. The synthesis of those findings and the research presented here illustrate the importance of the following to downscaling of wind climates: (1) Variations in simulation of the predictor variables and large-scale climate by the different AOGCM. (2) Temporal variations (at the decadal time scale) of the predictor variables. (3) Further and improved evaluation of downscaling techniques.

Accordingly, future work will focus on application of this empirical downscaling technique to AOGCM simulations of the entire 21st century to provide a more complete description of decadal variability in downscaled wind speeds and more detailed comparisons of dynamically and empirically downscaled wind speeds.

Acknowledgements. We acknowledge the international modeling groups for providing their data for analysis, the Program for Climate Model Diagnosis and Intercomparison (PCMDI) for collecting and archiving the model data, the JSC/CLIVAR Working Group on Coupled Modelling (WGCM) and their Coupled Model Intercomparison Project (CMIP) and Climate Simulation Panel for organizing the model data analysis activity, and the IPCC WG1 TSU for technical support. The IPCC Data Archive at Lawrence Livermore National Laboratory is supported by the Office of Science, U.S. Department of Energy. Limited financial support for this research was provided by 'Impacts of Climate Change on Renewable Energy Sources and their Role in the Energy System: 2003-2006' project funded by the Nordic Energy Research. The computational component of the research was made possible by the following grants to Indiana University from IBM (Shared University Research) and the National Science Foundation (grant \# 0116050).

\section{LITERATURE CITED}

Allen M, Ingram W (2002) Constraints on future changes in climate and the hydrologic cycle. Nature 419:224-232

Ambrose J, Vergun D (1997) Simplified building design for wind and earthquake forces, 3rd edn. Wiley, London

Arbogast AF, Scull P, Schaetzl RJ, Harrison J, Jameson TP, Crozier S (1997) Concurrent stabilization of some interior dune fields in Michigan. Phys Geogr 18:63-79

Benestad RE (2002) Empirically downscaled multimodel ensemble temperature and precipitation scenarios for Norway. J Clim 15:3008-3027

Bogardi I, Matyasovszky I (1996) Estimating daily wind speed under climate change. Solar Energy 57:239-248

Brabson B, Lister DH, Jones PD, Palutikof JP (2005) Soil moisture and predicted spells of extreme temperatures in Britain. J Geophys Res 110:doi:10.1029/2004JD005156

Delworth TL, Broccoli A, Rosati A, Stouffer RJ and 38 others (2005) GFDL's CM2 global coupled climate models - Part 1: Formulation and simulation characteristics. J Clim (in press)

de Rooy WC, Kok K (2004) A combined physical-statistical approach for the downscaling of model wind speeds. Weather Forecast 19:485-495

Global Atmospheric Model Development Team GFDL (2004) The new GFDL global atmosphere and land model AM2/LM2: Evaluation with prescribed SST simulations. J Clim 17:4641-4673

Goddard L, Mason S, Zebiak S, Ropelewiski C, Basher R, Cane M (2001) Current approaches to seasonal-to-interannual forecasting. Int J Climatol 21:1111-1152

Hanson CE, Palutikof JP, Davies TD (2004) Objective cyclone climatologies of the North Atlantic-a comparison between the ECMWF and NCEP reanalyses. Clim Dyn 22: $757-769$

Hsu SA (1988) Coastal meteorology. Academic Press, London

Huth R (2005) Downscaling of humidity variables: a search for suitable predictors and predictands. Int J Climatol 25: $243-250$

IPCC (2000) Emissions scenarios, 2000. Cambridge University Press, Cambridge

Johnson NL, Kotz S, Blakkrishnan N (1995) Continuous univariate distributions, Vol 2. Wiley series in probability and statistics, Wiley \& Sons, London

Jungo P, Goytette S, Beniston M (2002) Daily wind gust speed probabilities over Switzerland according to three types of synoptic circulation. Int J Climatol 22:485-499

Kharin V, Zwiers FW (2000) Changes in the extremes in an ensemble of transient climate simulations with a coupled atmosphere-ocean GCM. J Clim 13:3760-3788

Kidson JW, Thompson CS (1998) A comparison of statistical and model-based downscaling techniques for estimating local climate variations. J Clim 11:735-753

Klink K (2002) Trends and interannual variability of wind speed distributions in Minnesota. J Clim 15:3311-3317

Knippertz P, Ulbrich U, Speth P (2000) Changing cyclones and surface wind speeds over the North Atlantic and Europe in a transient GHG experiment. Clim Res 15: 109-122

Lionello P, Nizzero A, Elvini E (2003) A procedure for estimating wind waves and storm-surge climate scenarios in a regional basin: the Adriatic Sea case. Clim Res 23:217-231

Lott N, Baldwin R, Jones P (2001) The FCC integrated surface hourly database, a new resource of global climate data. NCDC technical report \# 2001-01, US Dept of Commerce, NCDC, Asheville, NC (available at http:// www1.ncdc.noaa.gov/pub/data/techrpts/tr2000101/tr200 1-01.pdf) 
Lozano I, Devoy R, May W, Andersen U (2004) Storminess and vulnerability along the Atlantic coastlines of Europe: analysis of storm records and of greenhouse gases induced climate scenario. Mar Geol 210:205-225

Lunneborg CE (2000) Data analysis by resampling - concepts and applications. Duxbury Press, Pacific Grove, CA

Mearns LO, Bogardi I, Giorgi F, Matyasovszky I, Palecki M (1999) Comparison of climate change scenarios generated from regional climate model experiments and statistical downscaling. J Geophys Res 104:6603-6621

Nilsson C, Stjernquist I, Barring L, Schlyter P, Jonsson A, Samuelsson H (2004) Recorded storm damage in Swedish forests 1901-2000. Forest Ecol Manag 199:165-173

Numaguti A, Takahashi M, Nakajima T, Sumi A (1997) Description of CCSR/NIES Atmospheric General Circulation Model. CGER's Supercomputer Monograph Report, Center for Global Environmental Research, National Institute for Environmental Studies, \#3, NIES, Yokohama

Palmer TN, Räisänen J (2002) Quantifying the risk of extreme seasonal precipitation events in a changing climate. Nature 415:512-514

Pan Z, Arritt RW, Takle ES, Gutowski WJ Jr, Anderson CJ, Segal M (2004) Altered hydrologic feedback in a warming climate introduces a warming hole. Geophys Res Lett 31:doi:10.1029/2004GL020528

Pryor SC, Barthelmie RJ (2003) Long term trends in near surface flow over the Baltic. Int J Climatol 23:271-289

Pryor SC, Barthelmie RJ, Kjellström E (2005a) Analyses of the potential climate change impact on wind energy resources in northern Europe using output from a Regional Climate Model. Clim Dyn (in press)

Pryor SC, Barthelmie RJ, Schoof JT (2005b) Inter-annual variability of wind indices across Europe. Wind Energy (in press)

Pryor SC, Schoof JT, Barthelmie RJ (2005c) Empirical downscaling of wind speed probability distributions. J Geophys Res (in press)

Räisänen J, Hansson U, Ullerstig A, Doscher R and 5 others (2004) European climate in the late twenty-first century: regional simulations with two driving global models and two forcing scenarios. Clim Dyn 22:13-31

Sailor D, Hu T, Li X, Rosen J (2000) A neural network approach to local downscaling of GCM output for assess-

Editorial responsibility: Robert Davis, Charlottesville, Virginia, USA ing wind power implications of climate change. Renew Energy 19:359-378

Schmidt GA, Ruedy R, Hansen JE, Aleinov I and 31 others (2005) Present day atmospheric simulations using GISS ModelE: Comparison to in-situ, satellite and reanalysis data. J Clim (in press)

Simmonds I, Keay K (2002) Surface fluxes of momentum and mechanical energy over the North Pacific and North Atlantic Oceans. Meteorol Atmos Phys 80:1-18

Simmons AJ, Gibson JK (2000) The ERA-40 Project Plan. ECMWF, Reading (available at www.ecmwf.int/)

Takle ES, Brown JM (1978) Note on the use of Weibull statistics to characterize wind-speed data. J Appl Meteorol 17: $556-559$

Taylor KE (2001) Summarizing multiple aspects of model performance in a single diagram. J Geophys Res Atmos 106:7183-7192

Weisse R, Von Storch H, Feser F (2005) Northeast Atlantic and North Sea storminess as simulated by a regional climate model during 1958-2001 and comparison with observations. J Clim 18:465-479

Wilby RL, Charles SP, Zorita E, Timbal B, Whetton P, Mearns LO (2004) Guidelines for use of climate scenarios developed from statistical downscaling methods (available at http: //ipcc-ddc.cru.uea.ac.uk/guidelines/dgm_no2_v1_09_2004. pdf

Yan Z, Bate S, Chandler R, Ishram V, Wheater H (2002) An analysis of daily maximum wind speed in northwestern Europe using generalized linear models. J Clim 15: 2073-2088

Yang JY, Comiso J, Walsh D, Krishfield R, Honjo S (2004) Storm-driven mixing and potential impact on the Arctic Ocean. J Geophys Res 109:doi:10.1029/2001JC001248

Yukimoto S, Noda A (2002) Improvements of the Meteorological Research Institute global ocean-atmosphere coupled GCM (MRI-CGCM2) and its climate sensitivity, GCER's supercomputer activity report 10, 37-44, NIES, Yokohamma (available at www.mri-jma.go.jp/Dep/cl/cl4/publications/yukimoto_CGER2002.pdf)

Yukimoto S, Noda A, Kitoh A, Sugi M and 5 others (2001) The new Meteorological Research Institute coupled GCM (MRI-CGCM2) - model climate and variability. Pap Meteorol Geophys 51:47-88

Submitted: April 13, 2005; Accepted: August 10, 2005

Proofs received from author(s): September 5, 2005 